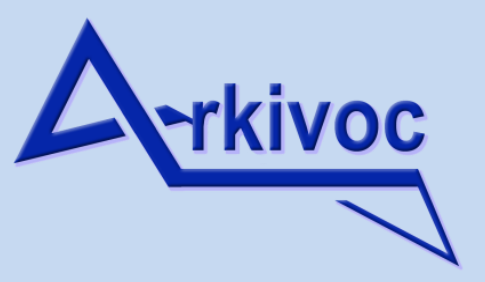

Free to Authors and Readers
A Platinum Open Access Journal for Organic Chemistry
Review

Arkivoc 2021, part v, 110-137

\title{
Recent advances in the synthesis of taxoids: $2015-2020$
}

\author{
Mohamed F. El-Mansy ${ }^{a, b}$ and William A. Donaldson*c
}

aOrganometallic and Organometalloid Chemistry Department, National Research Centre, 12622 Cairo, Egypt ${ }^{b}$ Department of Chemistry Department of Molecular Biosciences, Center for Molecular Innovation and Drug

Discovery, Northwestern University, Evanston, Illinois 60208-3113 USA

'Department of Chemistry, Marquette University, P. O. Box 1881, Milwaukee, WI 53201-1881 USA

Email: william.donaldson@marquette.edu

Dedicated to Prof. Peter A. Jacobi for his lifetime contributions to organic synthesis

Received 02-17-2021

Accepted 03-27-2021

Published on line 04-20-2021

\section{Abstract}

Taxol is a highly oxygenated, polycyclic diterpene first isolated from the bark of the Pacific yew tree. The impressive antitumor activity of this compound led to intense synthetic activity over the past 30 years. The first syntheses were reported more than 25 years ago, and earlier synthetic efforts have been amply reviewed. This review will focus on the literature for the period 2015-2020 including formal and total syntheses of taxol, 1-hydroxytaxinine, taxabaccatin III, and canataxpropellane.

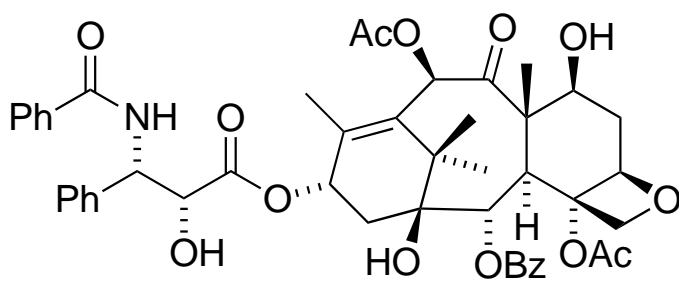

Taxol

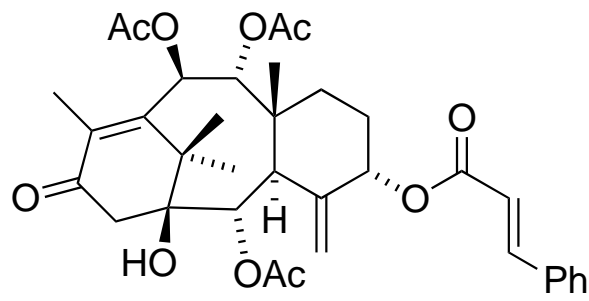

1-Hydroxytaxinine

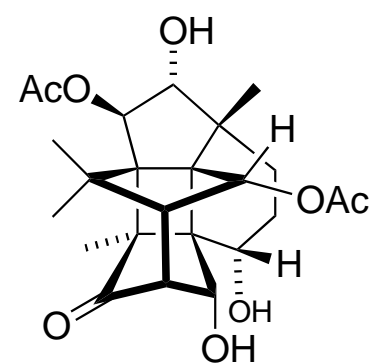

Canataxpropellane

Keywords: total synthesis, taxane-type diterpenes 


\section{Table of Contents}

1. Introduction

2. Formal Syntheses

2.1 Nakada formal synthesis of taxol $(A+C \rightarrow A C \rightarrow A B C \rightarrow A B C D)$

2.2 Chida formal synthesis of taxol $(A+C \rightarrow A C \rightarrow A B C \rightarrow A B C D)$

3. Total Syntheses

3.1 Inoue total synthesis of 1-hydroxytaxinine $(A+C>A C \rightarrow A B C)$

3.2 Baran total synthesis of taxabaccatin III ( $A \rightarrow A B C \rightarrow$ oxidase phase)

3.2.1 Process improvements to the synthesis of taxadienone

3.2.2 Oxidase phase synthesis of taxabaccatin III

3.3 Baran total synthesis of taxol (oxidase phase)

3.4 Gaich total synthesis of canataxpropellane

4. Conclusions

\section{Introduction}

TaxolC or paclitaxel was first isolated in 1964 by Wall and co-workers from the extracts of the bark of Taxus brevifolia, also known as the pacific yew tree. ${ }^{1}$ This complex polycyclic molecule belongs to the taxane diterpene family, of which there are now more than 550 known compounds, ${ }^{2}$ and was found to have impressive activity against KB cells. In 1992, taxol was approved by the FDA for treatment of recurrent ovarian cancer and in 1994 for the treatment of breast cancer. It was also reported that taxol has a significant effect in the treatment of different types of cancer such as lung and liver cancer. ${ }^{3,4}$ The anti-cancer activity of taxol results from its ability to inhibit tumor cell proliferation through enhancement of tubulin polymerization and to act as a promotor of microtubule assembly which leads to the stabilization of microtubules. ${ }^{5}$

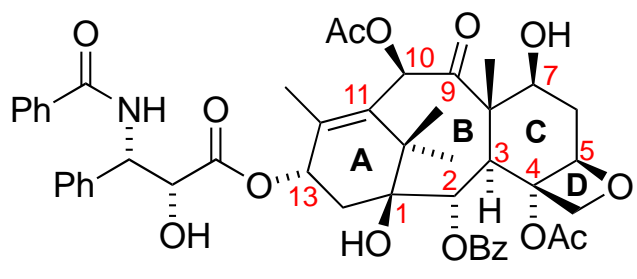

Taxol, 1

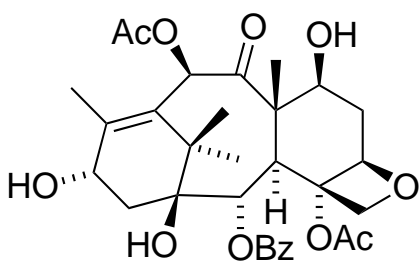

baccatin III, 2

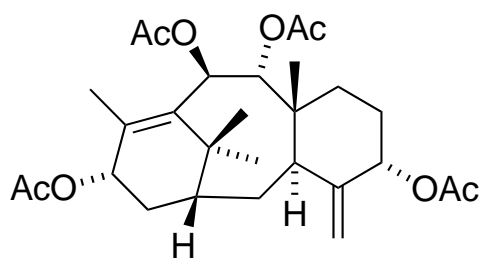

taxusin, 3

Figure 1. Structures of taxol (1), baccatin III (2), and taxusin (3).

Taxol 1, (Figure 1) is a highly oxygenated diterpene with a unique chemical structure characterized by a distorted eight-membered (B) ring fused with two peripheral 6-membered rings ( $A$ and $C$ ), referred to as a 6/8/6 skeleton, with an oxetane ring (D) fused with the $C$ ring. It has acetyl groups at $C 4$ and C10, a benzoyl group at C2, free hydroxyl groups at $\mathrm{C} 1$ and C7, and a unique $\beta$-phenylisoserine side chain at C13. The natural supply of taxol is relatively low (0.5-1 kg taxol from 4,500 kg pacific yew tree bark). Methanolysis of 1 leads to baccatin III (2); C7 protected analogs of $\mathbf{2}$ have been highly utilized in the penultimate steps for the synthesis of taxol. Due to the scarcity of natural taxol as well as its complex polycyclic structure, intense synthetic activity commenced resulting in the first total syntheses by the groups of Holton ${ }^{6,7}$ and Nicolaou. ${ }^{8-12}$ These 
were followed in the next 6 years by total syntheses from the groups of Danishefsky, ${ }^{13,14}$ Wender, ${ }^{15,16}$ Kuwajima, ${ }^{17,18}$ and Mukaiyama. ${ }^{19-22}$ In 2006 Takahashi's group reported a formal total synthesis which relied on use of an automated synthesizer. ${ }^{23}$ Another common synthetic target is the less oxidized taxusin (3). ${ }^{24-28}$ These syntheses have been amply covered in detail in several excellent review articles; ${ }^{29-34}$ the reader is directed to these for syntheses completed in the prior millennium. In addition, the various syntheses leading to the ? ?-phenylisoserine side chain of taxol has been reviewed. ${ }^{35}$ For this reason, the present review will focus on those total and formal syntheses of taxoids reported in the period 2015-2020.

\section{Formal Syntheses of Taxol}

\subsection{Nakada formal synthesis $(A+C \rightarrow A C \rightarrow A B C \rightarrow A B C D)$}

In early 2015, Nakada's group reported ${ }^{36,37}$ a formal total synthesis of taxol converging on cyclic carbonate 4 (Scheme 1) an intermediate in the Nicolaou ${ }^{8,12}$ synthesis. This was traced backwards to the tricyclic ketone 5. It was envisioned that the $\mathrm{C} 10-\mathrm{C} 11$ bond of $\mathbf{5}$ would be generated by a Pd-catalyzed intramolecular alkenylation of $\mathbf{6}$. The crucial C2-C3 bond formation would take place by addition of a vinyl lithium derived from 9 with aldehyde 8 . Both optically active precursors 8 and 9 would be generated by Baker's yeast mediated desymmetrizations of 2,2-disubstituted-1,3-cyclohexadiones.

(1)<smiles>C1CC2CC1C2</smiles>
5-TES ether of baccatin II
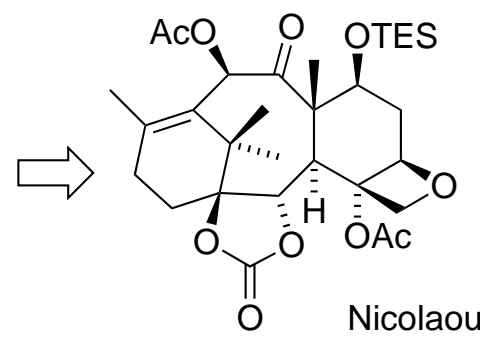
intermediate 4
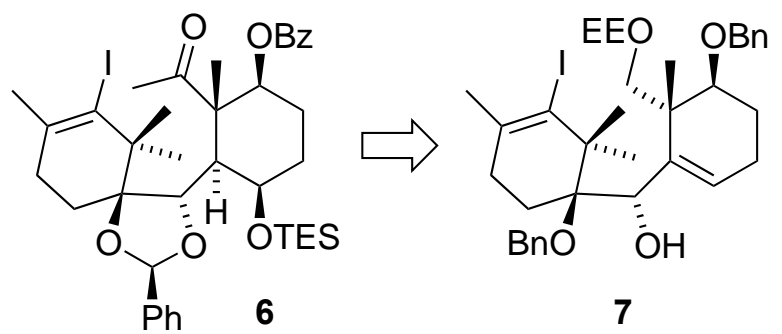

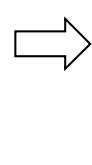

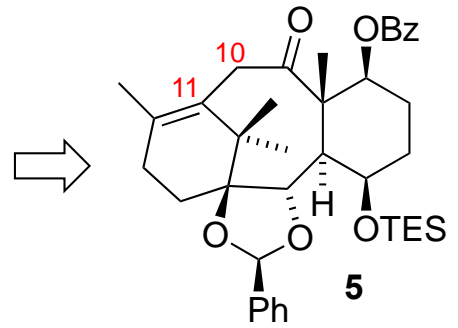
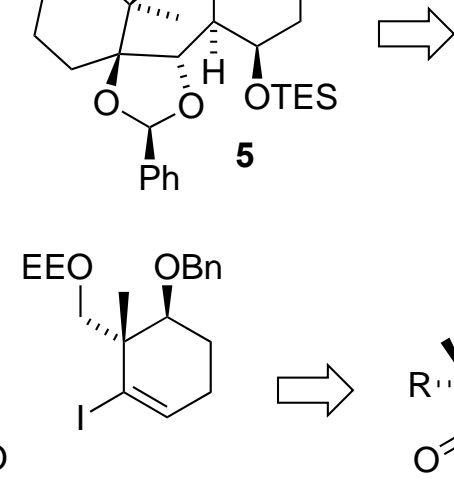

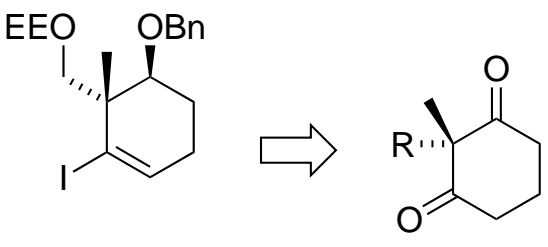

9
8

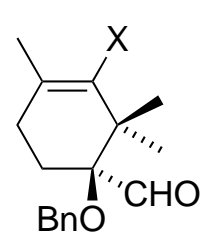

Scheme 1. Retrosynthetic analysis of taxol according to Nakada's approach.

Baker's yeast mediated reduction of 2,2-dimethyl-1,3-cyclohexandione ${ }^{38}$ gave $\mathbf{1 0}$ in good chemical yield and excellent enantioselectivity (Scheme 2). Silylation with chloromethyldimethylsilyl chloride, followed iodination under Finkelstein conditions afforded $11 .^{39}$ Lithium-halogen exchange of 11 triggered an intramolecular alkylation to generate the corresponding chiral tertiary bicyclic alcohol 12. Tamao oxidation followed by acetonide formation and Dess-Martin oxidation yielded ketone 13. $\alpha$-Methylation of 13 proceeded via the silyl enol ether, hydrazone generation and oxidation using iodine gave 14. Swapping the cyclic acetonide for a cyclic benzylidene acetal, followed by reductive cleavage at the less hindered oxygen and Dess-Martin oxidation gave $(+)-\mathbf{8}(R=I)$. While Nakata's group developed multiple routes to vinylhalides $\mathbf{8 , 3 7 , 4 0}$ the present route gave the highest overall yield and enantioselectivity. 

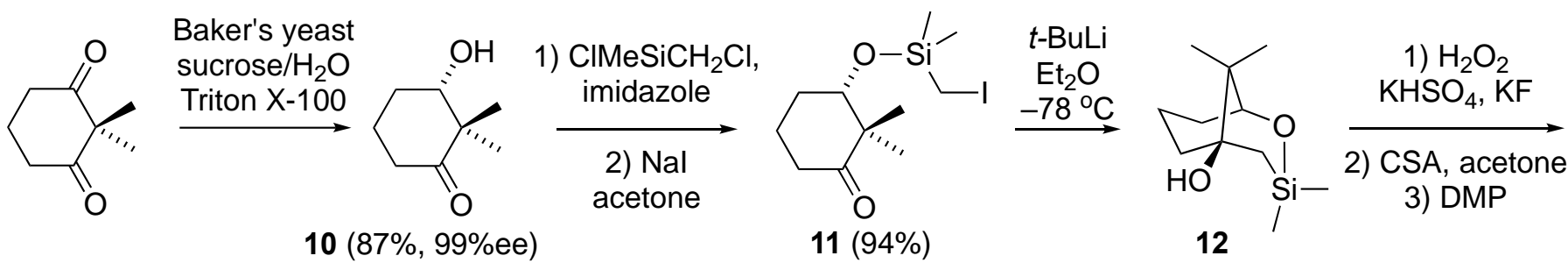

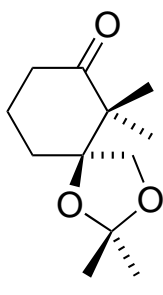

$13(85 \%)$

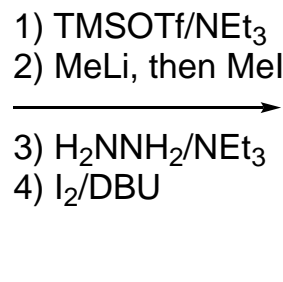

1) $\mathrm{TMSOTf}_{\mathrm{NEt}}$
2) $\mathrm{MeLi}$, then $\mathrm{Mel}$

3) $\mathrm{H}_{2} \mathrm{NNH}_{2} / \mathrm{NEt}_{3}$ 4) $\mathrm{I}_{2} / \mathrm{DBU}$

)

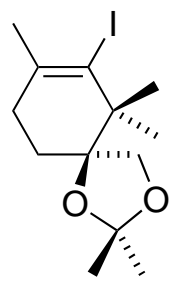

$14(80 \%)$
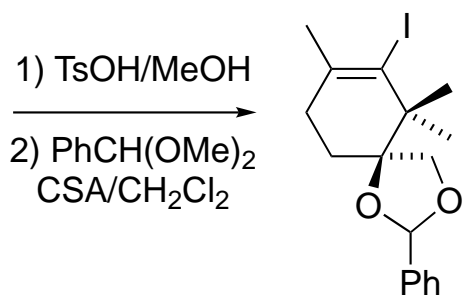

$(94 \%)$
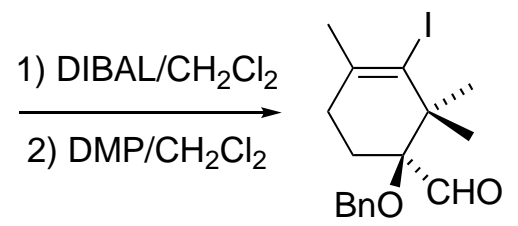

(+)-8 ( $\mathrm{R}=\mathrm{l}, 91 \%)$

Scheme 2. Synthesis of the ring A fragment $(+)-\mathbf{8}(R=I)$.

Preparation of the C ring fragment 9 commenced with Birch reduction of methyl 2,6dimethoxybenzoate (15); alkylation of the product with LDA followed by methyl iodide gave diene 16 (Scheme 3). ${ }^{36,37}$ Reduction of the ester with DIBAL, protection of the resulting $1^{\circ}$ alcohol as a benzyl ether and acidcatalyzed vinyl ether hydrolysis led to the achiral 1,3-cyclohexadione 17. As was the case for preparation of the A ring fragment, Baker's yeast reduction of $\mathbf{1 7}$ proceeded in good yield and excellent enantioselectivity to give (+)-18. A protecting group swap yielded benzylidene acetal 19. Transformation of 19 into the vinyl iodide 20 followed a procedure similar to previously used for $\mathbf{1 3}$ to 14. Similar reductive cleavage of the benzylidene acetal at the less hindered oxygen and protection of the resultant $1^{\circ}$ alcohol gave (+)-9.

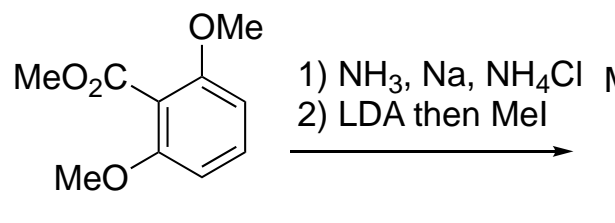

15

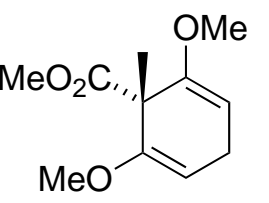

$16(87 \%)$
1) DIBAL-H

2) $\mathrm{NaH}, \mathrm{BnBr}$

3) $2 \mathrm{~N} \mathrm{HCl}$<smiles>O=C1CCCC(=O)C1(COCc1ccccc1)COc1ccccc1</smiles>

17 (81\%)
Baker's yeast $\mathrm{H}_{2} \mathrm{O}$, sucrose Triton X-100<smiles>O=C1CCC[C@@H](O)C1(COBr)COBr</smiles>

(+)-18

(75\%, 99\% ee)<smiles>O=C1CCC[C@@H]2O[C@@H](c3ccccc3)CO[C@H]12</smiles>

19 (88\%)

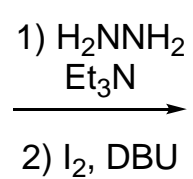

2) $I_{2}, \mathrm{DBU}$<smiles>IC1=CCC[C@@H]2O[C@@H](c3ccccc3)COC[C@H]12</smiles>

$20(87 \%)$

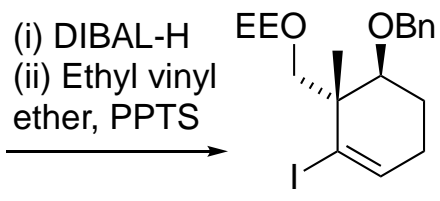

(+)-9 (94\%)

Scheme 3. Synthesis of ring C fragment (+)-9.

Lithium-halogen exchange of $(+)-9$ and reaction with aldehyde $(+)-8(R=I)$ gave $(+)-7$ as a single diastereomer (Scheme 4). ${ }^{36,37}$ The stereochemical outcome was rationalized on the basis of a chelationcontrolled addition (see red insert). Sharpless epoxidation of $\mathbf{7}$ catalyzed with $\mathrm{VO}(\mathrm{OEt})_{3}$ gave epoxide $\mathbf{2 1}$ as a single stereoisomer. Attempted ionic reduction of $\mathbf{2 1}\left(\mathrm{BF}_{3}-\mathrm{EtO}_{2} / \mathrm{NaBH}_{3} \mathrm{CN}\right)$ led surprisingly to the cyclic benzylidene acetal 22; the yield of this product could be improved by using only the Lewis acid. Nakada's group proposed that 22 is formed by a 1,5-hydride shift of the $\mathrm{BF}_{3}$ complexed epoxide, followed by 
deprotonation of the C2 hydroxyl group and nucleophilic attack on the benzyl cation (see blue insert). A sequence of oxidation of the C9 primary alcohol, protection of the C4 secondary alcohol, addition of methyl Grignard and oxidation afforded the methyl ketone 6. Formation of the eight-membered B ring was achieved by $\mathrm{Pd}$-catalyzed intramolecular alkenylation to give $\mathbf{5}$. While this $\mathrm{C}-\mathrm{C}$ bond formation proceeded in excellent yield, the catalyst loading (30\%) was relatively high.

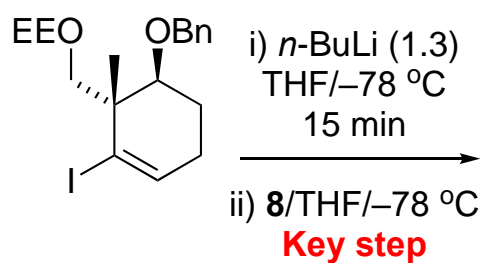

9

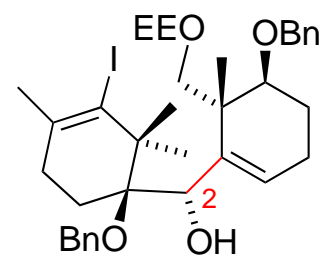

$(+)-7(95 \%)$

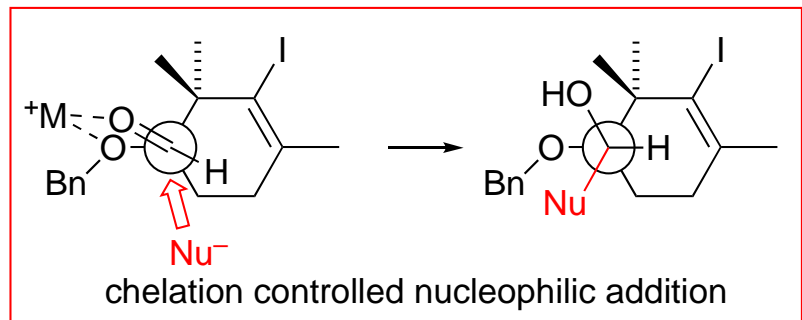

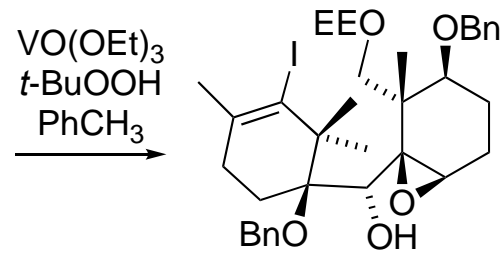

$21(87 \%)$

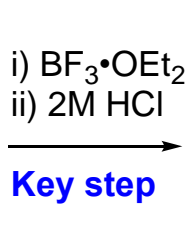

22
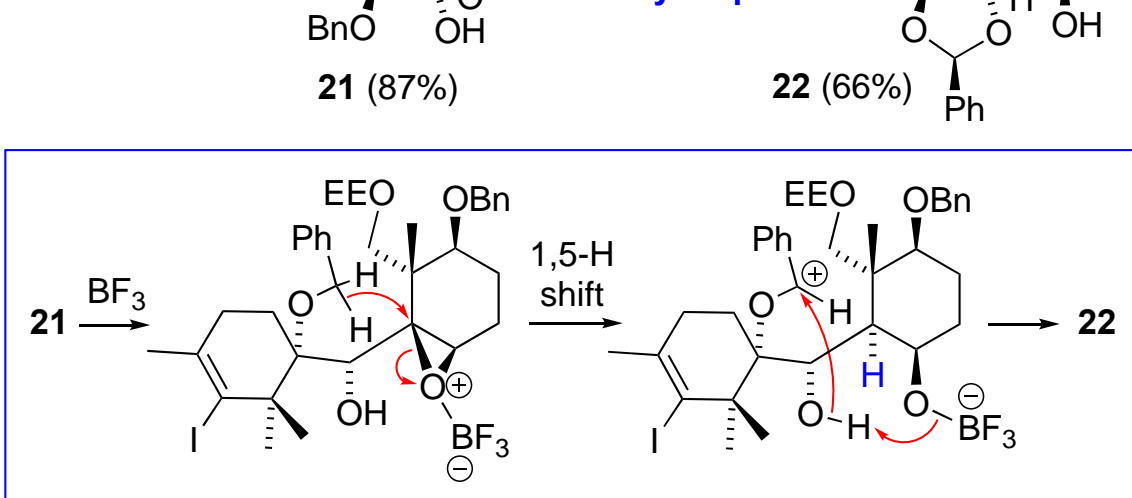
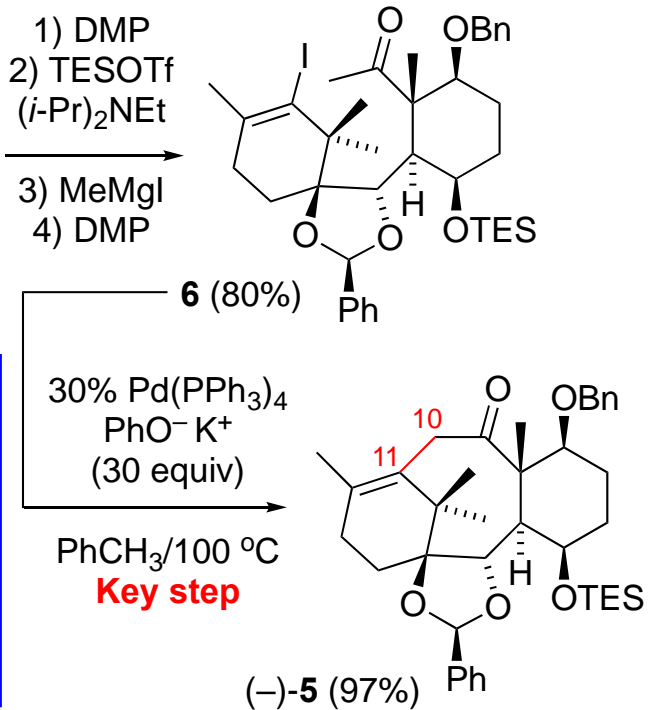

Scheme 4. Synthesis of the tricyclic core (-)-5 of taxol.

The C4 exocyclic methylene was constructed by deprotection of the C4 silyl ether, Dess-Martin oxidation and a Takai methenylation (Scheme 5). ${ }^{36,37}$ Selenium dioxide allylic oxidation of the less substituted exocyclic olefin of $\mathbf{2 3}$ proceeded in a stereoselective fashion to give $\mathbf{2 4}$. Transformation of $\mathbf{2 4}$ to the hydroxyoxetane followed a variation of the methodology utilized in Holton's synthesis. ${ }^{7}$ Thus, stereoselective dihydroxylation of allylic alcohol with stoichiometric $\mathrm{OsO}_{4}$ and acylation of the $1^{\circ}$ alcohol afforded 25 . 


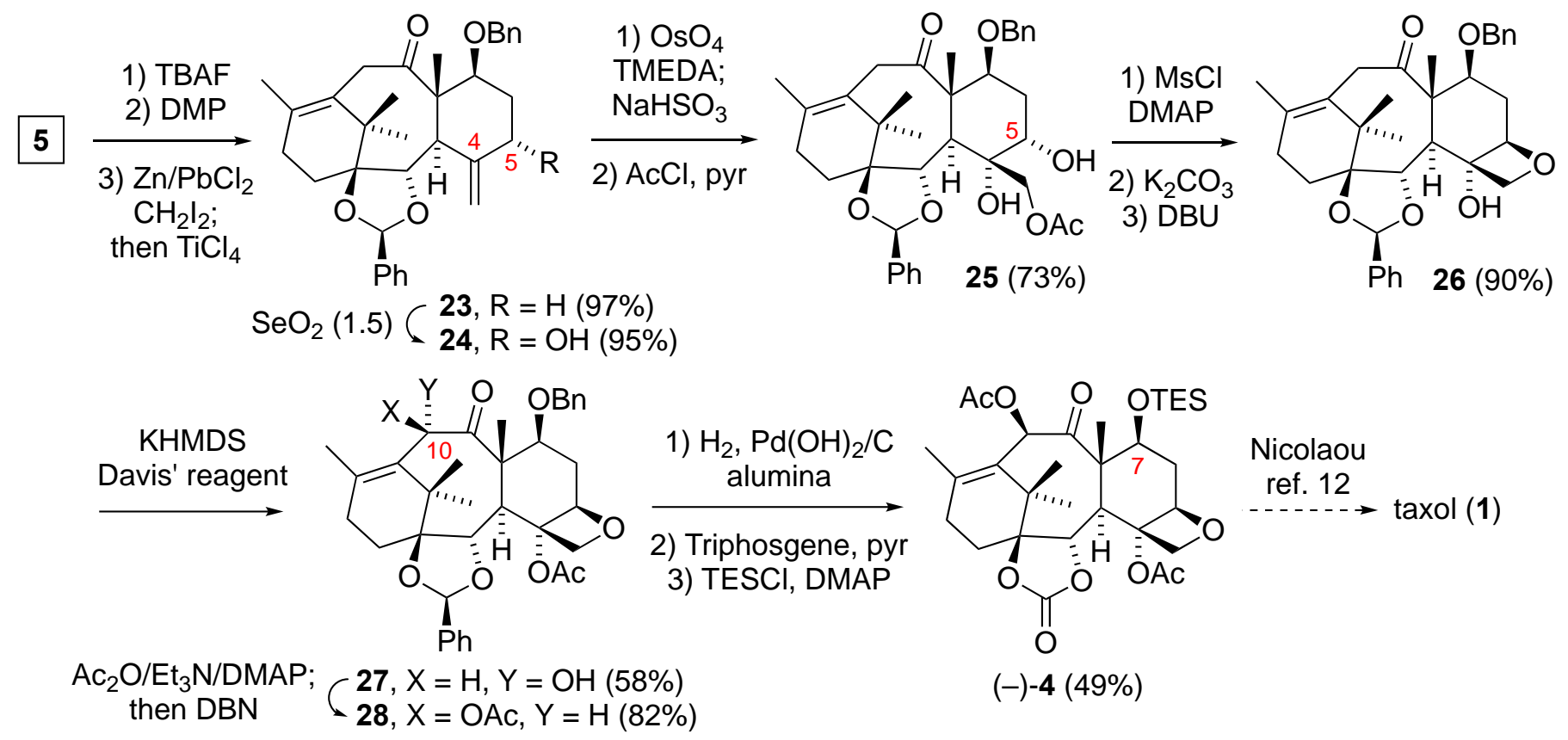

Scheme 5. Installation of the oxane ring and completion of the formal synthesis.

Mesylation of the C5 secondary alcohol, hydrolysis of the primary acetate and treatment with DBU afforded 26. Treatment of the enolate anion of $\mathbf{2 6}$ with 2-(phenylsulfonyl)-3-phenyl-oxaziridine (Davis reagent) introduced a hydroxyl group at $\mathrm{C} 10$, however this possessed the opposite stereochemistry to that desired for taxol. Acylation of this alcohol and epimerization with DBN produced 28. Reductive deprotection of the benzylidene acetal and the C7 benzyl ether was achieved using Pearlman's catalyst, reaction with triphosgene generated the cyclic carbonate ring and C7 hydroxyl protection as a TES ether rendered (-)-4, an intermediate in the Nicolaou total synthesis. ${ }^{12}$

The Nakada synthesis of chiral ABCD tetracyclic core of taxol required 49 steps from the commercially available achiral 2,2-dimethyl-1,3-cyclohexandione and 2,6-dimethoxy methyl benzoate resulting in $~ 0.91 \%$ overall yield. Approximately $1 / 3$ of the steps involved protection or deprotection with approximately $1 / 6$ of the steps utilized for oxidations or reductions.

\subsection{Chida formal synthesis $(A+C \rightarrow A C \rightarrow A B C \rightarrow A B C D)$}

Chida's group reported ${ }^{41-43}$ a formal synthesis of taxol converging on a tetracyclic intermediate (29) in Takahashi's ${ }^{23}$ formal synthesis (Scheme 6). A late-stage introduction of the oxetane ring was envisioned from tricyclic 30. Generation of the eight-membered B ring would be accomplished by a $\mathrm{Sml}_{2}$ mediated reductive cyclization of allylic benzoate 31. Marriage of hydrazine $\mathbf{3 2}$ and aldehyde $\mathbf{3 3}$ utilized an intermolecular Shapiro reaction pioneered in the Nicolaou synthesis. 8,10 The $A$ ring fragment $\mathbf{3 2}$ and $C$ ring fragment $\mathbf{3 3}$ would be synthesized from 1,3-cyclohexadienone $\mathbf{3 4}$ and tri-O-acetyl-D-glucal 35 respectively. 


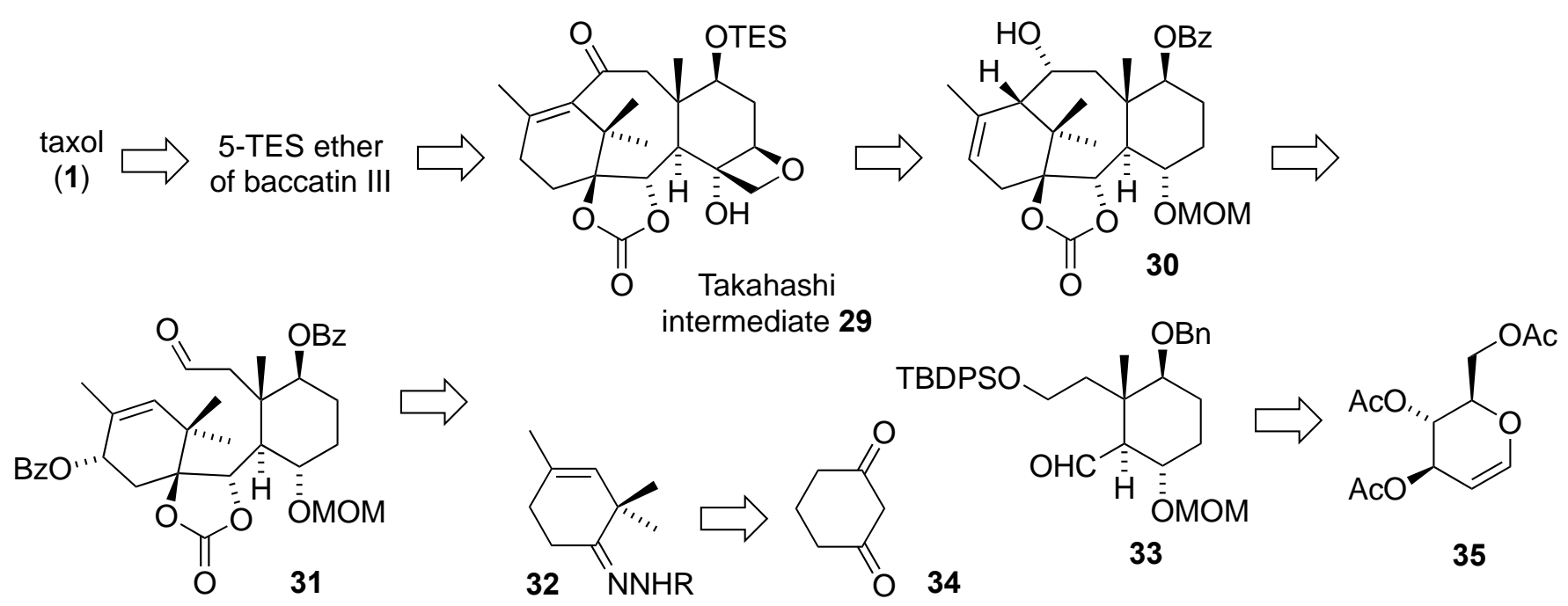

Scheme 6. Sato-Chida retrosynthetic analysis of taxol.

The preparation of hydrazone 32 from 34 (Scheme 7) followed a modification of Koskinen's procedure. ${ }^{44}$ To this end, double methylation of 34, followed formation of the mono ketal formation and reaction with tosylhydrazine afforded 36. Alkylation of $\mathbf{3 6}$ introduced the requisite methyl group at C12; subsequent Shapiro reaction with protic work up gave the olefin. Deprotection of the ketal followed by hydrazone formation with 2,4,6-tri-isopropylbenzenesulfonylhydrizine gave 32.

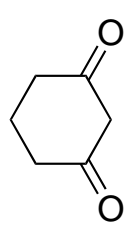

34
(1) $\mathrm{K}_{2} \mathrm{CO}_{3}$ (1.99), Mel (3)

(2) 2,2-dimethyl-1,3propanediol, $\mathrm{TsOH}$

(3) $\mathrm{TsNHNH}_{2} / \mathrm{EtOH}$ $47 \%$

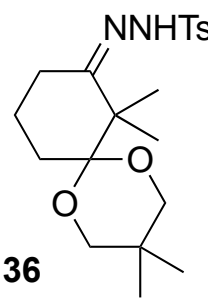

(1) $n$-BuLi (2.1); then Mel (1.9); then $n$-BuLi (4); then $\mathrm{H}_{2} \mathrm{O}$ workup

(2) $\mathrm{HCl}$ aq.

(3) $\mathrm{ArSO}_{2} \mathrm{NHNH}_{2}$

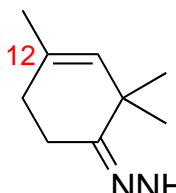
$\mathrm{NNHSO}_{2} \mathrm{Ar}$

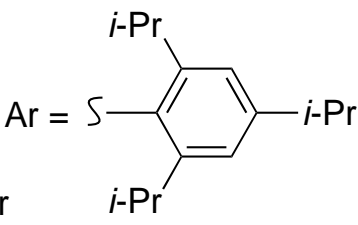

$32(61 \%)$

Scheme 7. Synthesis of ring A fragment 32.

Ring C fragment 33 was synthesized from tri- $O$-acetyl- $D$-glucal 35 by Ferrier rearrangement with methanol, followed by catalytic hydrogenation, according to the literature procedure ${ }^{45}$ (Scheme 8). Hydrolysis of the acetate groups, Appel iodination of the primary alcohol, and protection of the secondary alcohol gave 37. Elimination with potassium $t$-butoxide, a carbo-Ferrier rearrangement, ${ }^{46}$ and $\beta$-elimination with mesyl chloride/ $\mathrm{NEt}_{3}$ gave 6(S)-benzyloxy-2-cyclohexenone (38). Carbonyl transposition ${ }^{47}$ with methyl lithium followed by PCC oxidation generated 39. Copper catalyzed 1,4-addition of vinyl magnesium chloride occurred on the face of the enone opposite to the 4-benzyloxy substituent. The resultant enolate was trapped in situ as the silyl enol ether; Lewis acid catalyzed aldol condensation with formalin gave a separable mixture of the desired 40 (60\%) along with the C3-epimer (41, 23\%, taxol numbering). Protection of the major diastereomer (40) as its THP ether, followed by Luche reduction gave an equimolar, but separable mixture of the desired secondary alcohol $\mathbf{4 3}$ and the diastereomer $\mathbf{4 4}$. Oxidation of $\mathbf{4 4}$ under Ley conditions ${ }^{48}$ regenerated $\mathbf{4 2}$. Finally, protection of the secondary alcohol, regioselective hydroboration/oxidation, protection with $t$ butyldiphenylsilyl chloride, hydrolysis of the THP mixed acetal and Ley oxidation generated the requisite aldehyde 33. While this route generated an optically pure fragment, drawbacks to this approach include 
overall length (16 steps) and two steps with relatively low diastereoselectivity (39 to $\mathbf{4 0 / 4 1}=2.6: 1 \mathrm{dr}$ and $\mathbf{4 0}$ to 43/44 = 1:1 dr).<smiles>COC[C@@H]1OC=C[C@@H](OC(C)(C)C)[C@H]1OC(C)(C)C</smiles>

35
1) $\mathrm{MeOH}, \mathrm{BF}_{3} \cdot \mathrm{OEt}_{2}$;

2) $\mathrm{H}_{2}, \mathrm{Pd} / \mathrm{C}$

3) $\mathrm{MeONa}, \mathrm{MeOH}$; then $\mathrm{I}_{2}, \mathrm{Ph}_{3} \mathrm{P}$, imidazole

4) $\mathrm{NaH}$; $\mathrm{BnBr}, \mathrm{n}-\mathrm{Bu}_{4} \mathrm{NI}$<smiles>CO[C@H]1CC[C@@H](OBr)[C@H](CI)O1</smiles>

$37(72 \%)$
1) $t$-BuOK; then $\mathrm{Hg}\left(\mathrm{OCOCF}_{3}\right)_{2}$

2) $\mathrm{MsCl} / \mathrm{Et}_{3} \mathrm{~N}$<smiles>O=C1C=CCC[C@@H]1Br</smiles>

1) MeLi<smiles>CC1=CC(=O)CC[C@H]1Br</smiles>

$39(86 \%)$ (i) Cul, $\mathrm{MgCl}$ then $\mathrm{TMSCl}, \mathrm{Et}_{3} \mathrm{~N}$ (ii) $\mathrm{Sc}(\mathrm{OTf})_{3}, \mathrm{H}_{2} \mathrm{C}=\mathrm{O}$
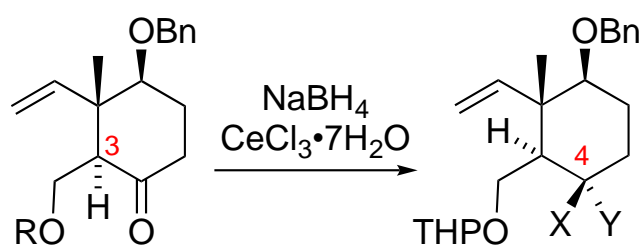

1) $\mathrm{MOMCl}, i-\mathrm{Pr}_{2} \mathrm{NEt}(98 \%)$ 2) Thexylborane; then $\mathrm{NaOH} / \mathrm{H}_{2} \mathrm{O}_{2}(90 \%)$ 3) TBDPSCl/imidazole (94\%)

4) $\mathrm{AcOH} / \mathrm{MeOH}(89 \%)$

5) TPAP/NMO (96\%)

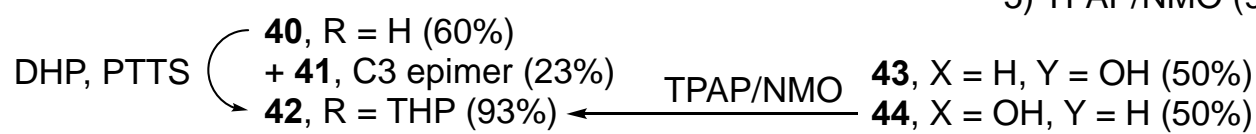

Scheme 8. Synthesis of the ring C fragment 33.

Coupling of $\mathbf{3 3}$ with a two-fold excess of the vinyl anion generated from hydrazine $\mathbf{3 2}$ gave the allylic alcohol 45 as a single diastereomer (Scheme 9)..$^{42,43}$ The stereochemical outcome is similar to that observed in the syntheses of Nicolaou, ${ }^{8,11}$ Danishefsky ${ }^{13,14}$ and Kuwajima17,18 where a Shapiro reaction was utilized to generate the $\mathrm{C} 2-\mathrm{C} 3$ bond. Stereoselective epoxidation catalyzed by $\mathrm{VO}(\mathrm{acac})_{2}$, followed by regioselective reduction gave the vic-diol which was protected as the cyclic carbonate $\mathbf{4 6}$. Oxidation of $\mathbf{4 6}$ with a large excess of chromium trioxide in the presence of 3,5-dimethylpyrazole proceeded predominantly at both the C13 allylic position as well as at the $C 7$ benzyl ether to generate 48, along with a lesser amount of partially oxidized 47. Subjecting 47 to further treatment with $\mathrm{CrO}_{3} / \mathrm{DMP}$ gave additional $\mathbf{4 8}$. Stereoselective reduction of 48 at $\mathrm{C} 13$, protection of the resultant secondary alcohol as the benzoyl ester, deprotection of the silyl ether and oxidation of the primary alcohol afforded $\mathbf{3 1}$ and set the stage for the final key step. Cyclization was achieved using an excess of $\mathrm{Sml}_{2}$ to afford a mixture of diastereomeric homoallylic alcohols $\mathbf{3 0}$ and $\mathbf{4 9}$ (66\%, 1:1.5 ratio). The structural assignments of $\mathbf{3 0}$ and $\mathbf{4 9}$ were confirmed by X-ray crystallography. An additional byproduct (50) resulted from formation of a $\mathrm{C}-\mathrm{C}$ bond between $\mathrm{C} 10$ and $\mathrm{C} 13$. Formation of product $\mathbf{5 0}$ is reminiscent of the challenges faced by the Nicolaou group in their McMurry coupling to generate the C9-C10 bond. ${ }^{8,11} \mathrm{Chida}$ found that use of HMPA as a co-solvent was crucial for the success of this reaction, as THF alone led to simply reduction of the aldehyde. Oxidation of 49 gave 51; all attempts to isomerize the olefin into conjugation failed. DFT calculations of simplified models of $\mathbf{5 1}$ and $\mathbf{5 2}$ indicated that the conjugated olefin (52) was less stable than the skipped enone (51). 


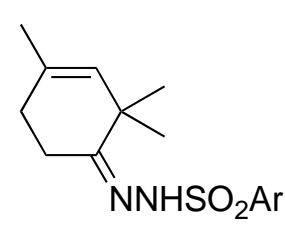

32

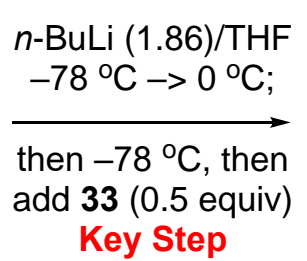

Key Step

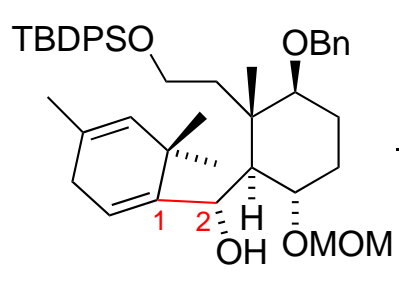

$45(92 \%)$

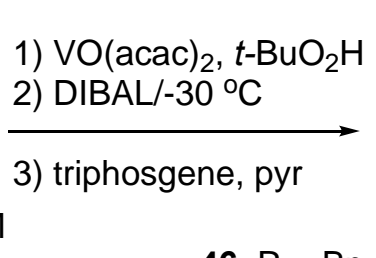

46, $R=B n(82 \%)$

47, $\mathrm{R}=\mathrm{Bz}$
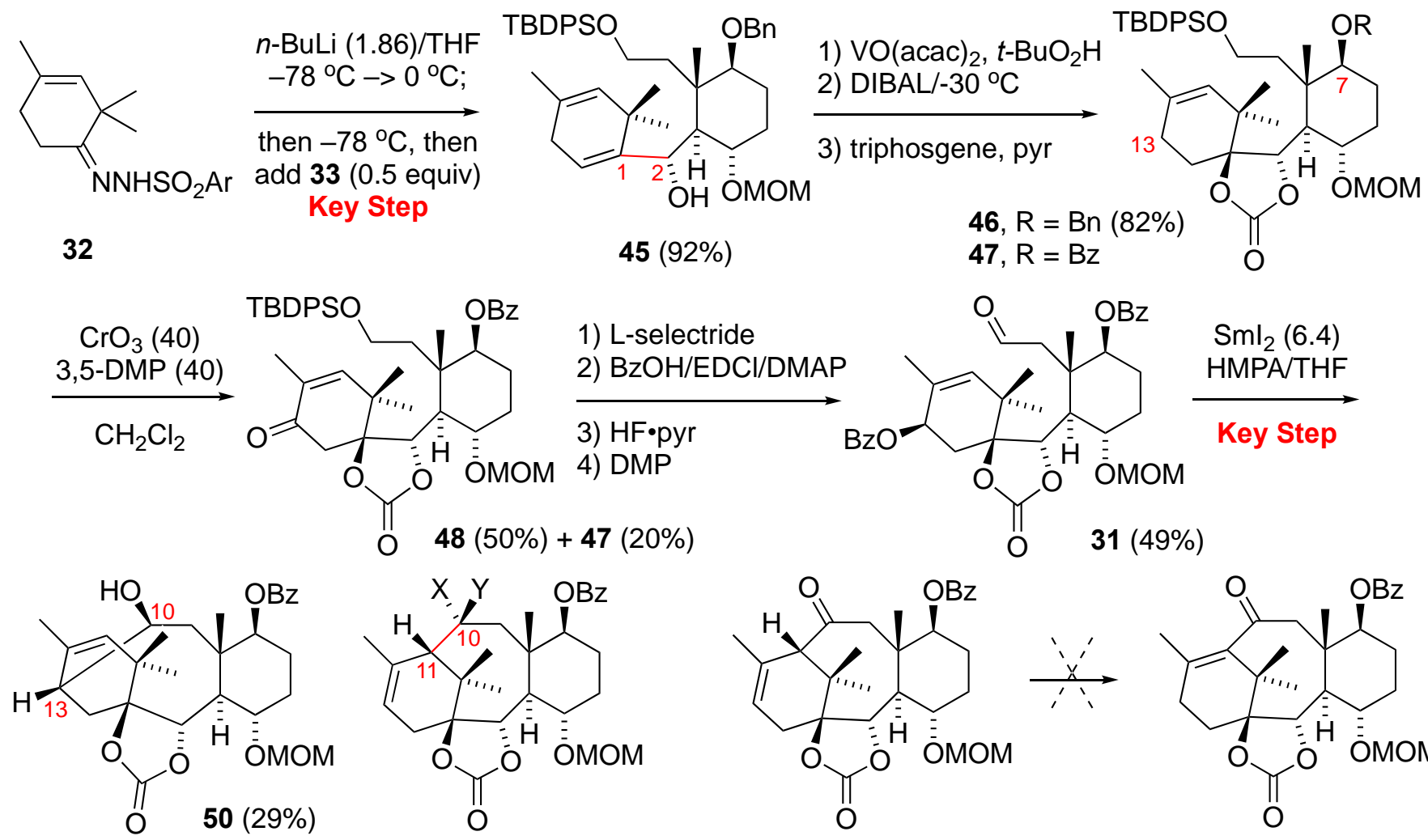

49, $\mathrm{X}=\mathrm{H}, \mathrm{Y}=\mathrm{OH}(26 \%) \quad$ TPAP/NMO

$30, \mathrm{X}=\mathrm{OH}, \mathrm{Y}=\mathrm{H}(40 \%) \stackrel{\mathrm{PAP} / \mathrm{NMO}}{\longrightarrow} 51(77 \%)$
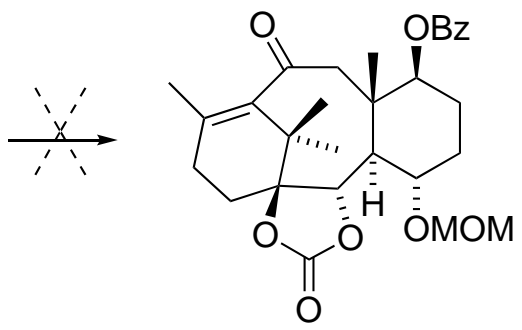

52

Scheme 9. Sato-Chida coupling of fragments $\mathbf{3 2}$ and $\mathbf{3 3}$ and closure of ring B.

Since isomerization of $\mathbf{5 1}$ to $\mathbf{5 2}$ failed, an alternative route to converge with Takahashi's intermediate was devised (Scheme 10). ${ }^{42,43}$ Stereoselective reduction of 51, and protection of the resultant alcohol gave the benzyl ether 53. Dihydroxylation of $\mathbf{5 3}$ with an excess of $\mathrm{OsO}_{4}$, followed by reaction with sodium hydride, carbon disulfide and iodomethane gave the bis-xanthate $\mathbf{5 4}$. Thermal double elimination of $\mathbf{5 4}$ led to the conjugated diene 55. Deprotection of the C4 methoxymethyl ether and oxidation to the ketone set the stage for eventual introduction of a C4 exocyclic methylene via an interrupted Peterson olefination. To this end, addition of the Grignard reagent from (chloromethyl)trimethylsilane yielded the tertiary alcohol 56. Reduction of $\mathbf{5 6}$ with hydrogen in the presence of Pearlman catalyst proceeded via addition at the less substituted C13C14 olefin as well as cleavage of the C10 benzyl ether; the resultant secondary alcohol was oxidized to a ketone, and elimination of the $\beta$-silylalcohol rendered the exocyclic olefin (57). The C7 benzoate ester was exchanged for a triethylsilyl ether over a three-step sequence to afford 58. Selenium dioxide allylic oxidation of the less substituted exocyclic olefin proceeded in a stereoselective fashion to give $\mathbf{5 9}$. Transformation of $\mathbf{5 9}$ to the hydroxyoxetane followed a variation of the methodology utilized in Holton's synthesis. ${ }^{7}$ Thus, mesylation of the C5 hydroxyl, stereoselective dihydroxylation of the exocyclic olefin and treatment with Hunig's base afforded 29. As an intermediate in Takahashi's formal synthesis, ${ }^{23}$ the cyclic carbonate present in 29 was opened with phenyl lithium, followed by acetylation of the C4 tertiary alcohol to generate $\mathbf{6 0}$, which is itself an intermediate in the Danishefsky total synthesis. ${ }^{13,14}$

The Chida synthesis of chiral $A B C D$ tetracyclic core of taxol required 31 steps from the commercially available achiral 1,3-cyclohexandione and chiral tri-O-acetyl-D-glucal resulted in $\sim 0.12 \%$ overall yield. Approximately $1 / 3$ of the steps involve protection or deprotection while approximately $1 / 6$ of the steps were utilized for oxidations or reductions. 

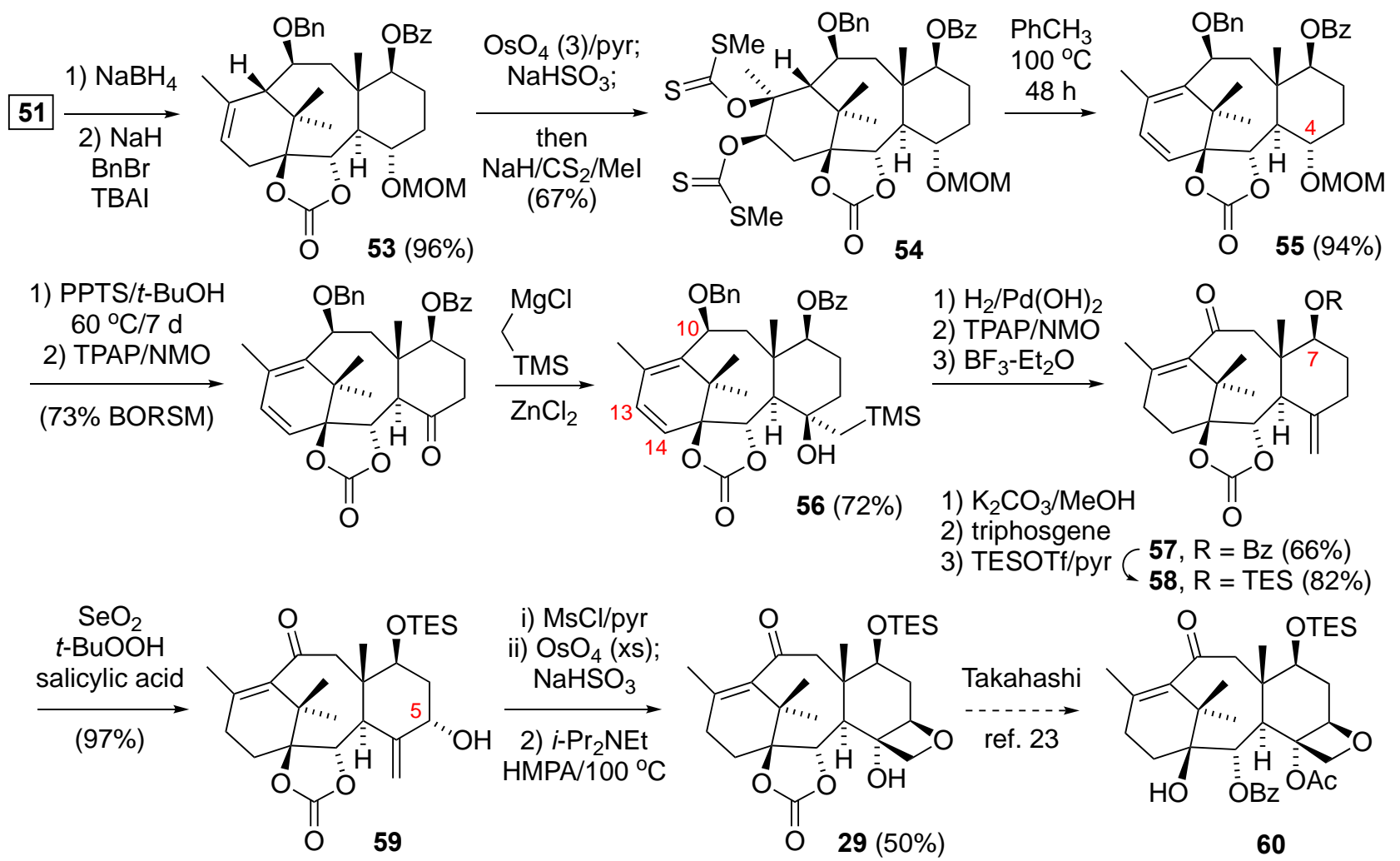

Danishefsky, ref. 13,14 taxol (1)

Scheme 10. Final steps of the Chida formal synthesis.

\section{Total Syntheses}

\subsection{Inoue total synthesis of 1-hydroxytaxinine $(A+C>A C \rightarrow A B C)$}

Inoue's group reported the first total synthesis of 1-hydroxytaxinine (61, Scheme 11). ${ }^{49}$ Their retrosynthetic analysis required the introduction of oxygen functionality at $\mathrm{C} 5, \mathrm{C} 7$ and $\mathrm{C} 13$ of a nearly complete carbon skeleton (62). They envisioned generation of the C1-C2 bond in the B ring by a pinacol coupling of the ketoaldehyde 63. This approach is relatively unique, as many of the other syntheses create the $\mathrm{C} 1-\mathrm{C} 2$ bond prior to formation of the central eight-membered ring. Precursor 63 would be accessed by a decarbonylative radical coupling of fragments 64 and 65.

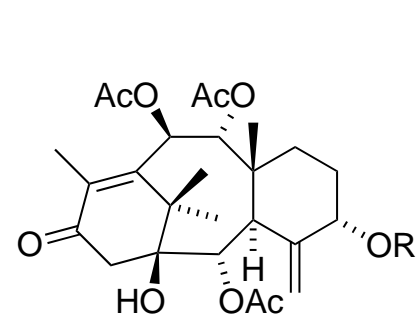

1-Hydroxytaxinine (61)

$\mathrm{R}=\mathrm{C}(\mathrm{O}) \mathrm{CH}=\mathrm{CHPh}$

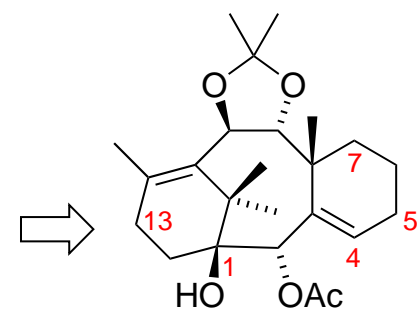

62

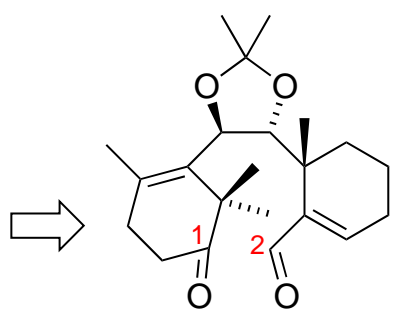

63

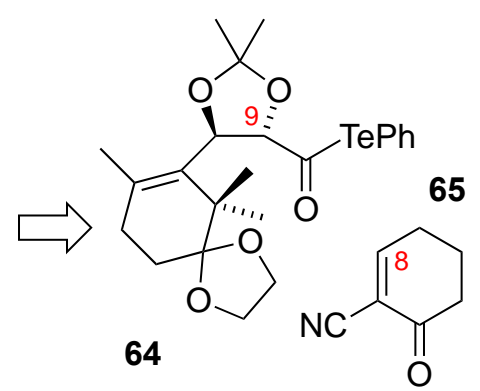

64

Scheme 11. Inoue retrosynthetic analysis of 1-hydroxytaxinine. 
The initial steps for preparation of the A ring fragment are similar to those utilized by Nakada ${ }^{36,37}$ (c.f. Scheme 2). Thus, mono-protection of 2,2-dimethyl-1,3-cyclohexadione followed by $\alpha$-methylation generated 66; hydrazone formation and treatment with iodine/DBU gave vinyl iodide 67 (Scheme 12). Heck reaction of 67 with an excess of methyl acrylate led to 68. Sharpless asymmetric dihydroxylation of dienoate 68 proceeded at the less substituted, albeit more electron-deficient olefin. Since the diol was not completely separable from methyl sulfonamide, the crude mixture was directly protected as acetonide derivative 69. Conversion of methyl ester 69 to an acyl telluride 64 required saponification, activation with $i$-butyl chloroformate, and reaction with phenyltelluride (prepared by reduction of diphenyl ditelluride). Reduction of the acyl telluride with triethylborane in an open-air reaction, proceeded with formation of the C8-C9 bond in a stereoselective fashion; oxidation of the product with DDQ restored the 2-cyano-2-cyclohexenone ring (70). The reductive decarbonylation of 64 proceeded via the acyl radical 71, and while decarbonylation of 72 immolated the $\mathrm{C} 9$ stereocenter, addition of the $\alpha$-alkoxy radical $\mathbf{7 2}$ proceeded from the less sterically hindered face with apparent stereo-retention (see magenta insert).

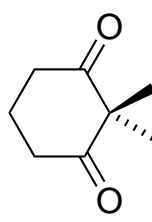

1) $\left(\mathrm{CH}_{2} \mathrm{OH}\right)_{2}$ CSA

2) $\operatorname{LiN}\left(\mathrm{SiMe}_{3}\right)_{2}$ $\mathrm{Mel}$

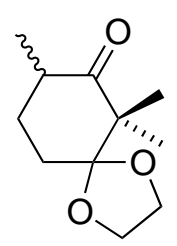

$66(66 \%)$

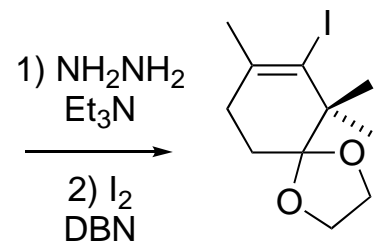

67 (55\%)

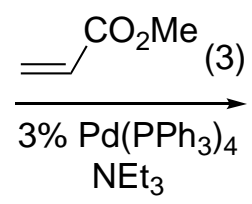

$\mathrm{NEt}_{3}$

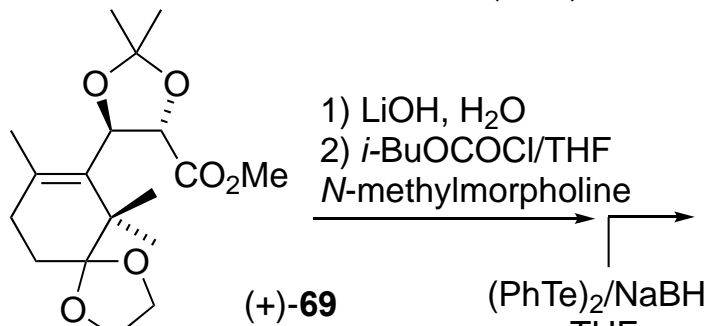

$(41 \%, 96 \%$ ee $)$

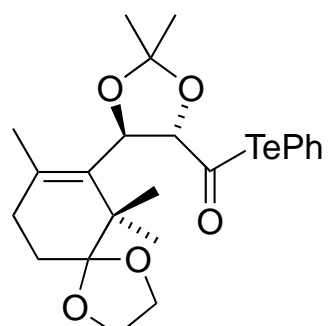

(-)-64 (91\%) i) $\mathrm{Et}_{3} \mathrm{~B} / \mathrm{C}_{6} \mathrm{H}_{6} / 50^{\circ} \mathrm{C}$ 2-cyano-2-cyclohexenone

ii) DDQ/2,6-lutidine key step

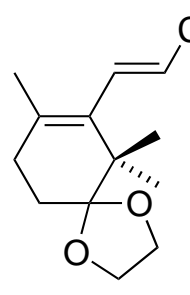

$68(94 \%)$
$\mathrm{CO}_{2} \mathrm{Me}$ 1) $\mathrm{AD}-$ mix$t-\mathrm{BuOH} / \mathrm{H}_{2} \mathrm{O}$ $\mathrm{MeSO}_{2} \mathrm{NH}_{2}$ $4 \mathrm{~d} / 23^{\circ} \mathrm{C}$

2) $\mathrm{Me}_{2} \mathrm{C}(\mathrm{OMe})_{2}$ PPTS

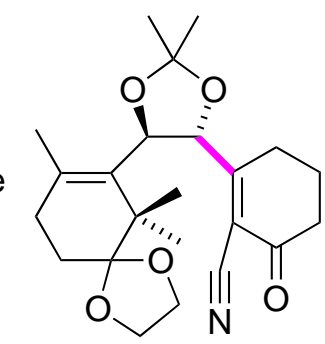

(+)-70 (65\%) $49 \%$ yield, $>99 \%$ ee after x'tal
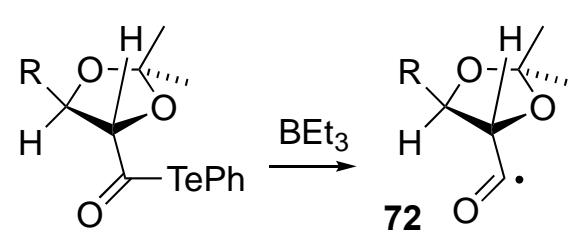
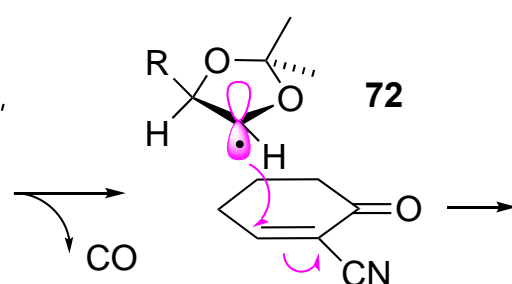

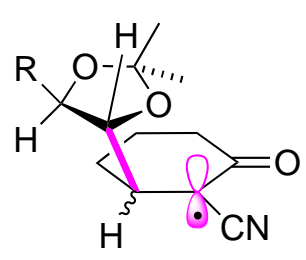

Scheme 12. Formation of precursor $\mathbf{7 0}$ via decarbonylative radical coupling reaction.

Conjugate addition of methyl Grignard in the presence of Cul to $\mathbf{7 0}$ proceeded predominantly on the ?? face (Scheme 13). ${ }^{49}$ Reduction of the resultant $\alpha$-cyano cyclohexanone, mesylation of the secondary alcohol and elimination with DBU gave the corresponding $\alpha, \beta$-unsaturated nitrile $\mathbf{7 1}$ as an inseparable mixture of diastereomers at C8. Reduction of the nitrile, followed by aqueous acidic work-up (for hydrolysis of the imine and cyclic ketal) led to a separable mixture of the desired stereoisomer (-)-63 and 72 . A TiCl $4 / \mathrm{Zn}$ mediated pinacol coupling of 63, after work-up with excess acetic anhydride, provided mono-acetate 62 as the major product along with minor amounts of diol 73. The structure of 62 was corroborated by X-ray crystal structure. The stereochemical outcome was rationalized by proposing that the transition state for $\mathrm{C} 1-\mathrm{C} 2$ bond formation 
on the si-face of C2 would be higher in energy (compared to the re-face) due to steric interactions between the Ti-O moiety with one of the gem-dimethyl groups at $\mathrm{C} 15$ as well as with the $\mathrm{C} 5$ hydrogen. The undesired diol 73 could be recycled to (-)-63 by glycol cleavage with $\mathrm{Pb}(\mathrm{OAc})_{4}$. Exhaustive allylic oxidation at both $\mathrm{C} 5$ and $\mathrm{C} 13$ was achieved with $\mathrm{CrO}_{3} / 3,5$-dimethylpyrazole to give 74 as the major product along with minor amounts of a product reflecting cleavage of the $\mathrm{C} 1-\mathrm{C} 15$ bond (75).

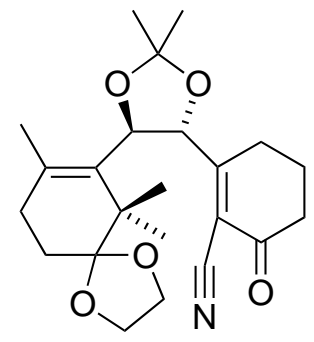

$(+)-70$
1) $\mathrm{MeMgBr} / \mathrm{Cul}$; then $\mathrm{NaBH}_{4}$ $\mathrm{EtOH}$

\section{2) $\mathrm{MsCl} / \mathrm{Et}_{3} \mathrm{~N}$;} then $\mathrm{DBU} / 100^{\circ} \mathrm{C}$

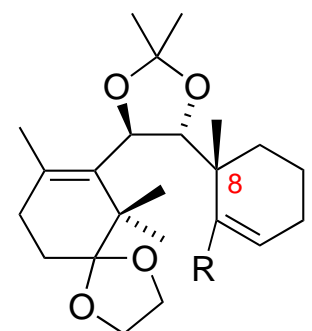

71, $\mathrm{R}=\mathrm{CN}+\mathrm{C} 8$ epimer $(7: 1)$

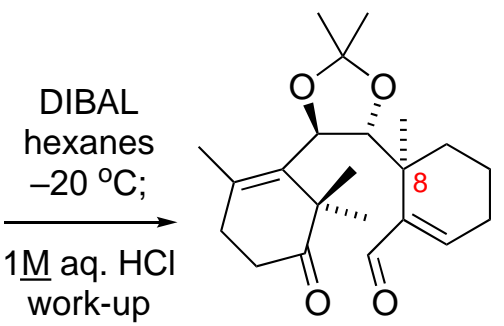

$72(<9 \%)$ separable

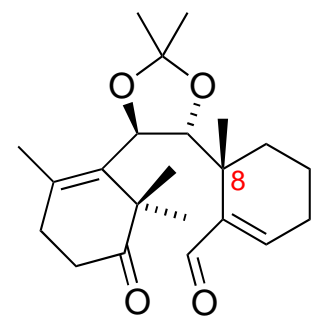

(-)-63 (61\%, three steps)

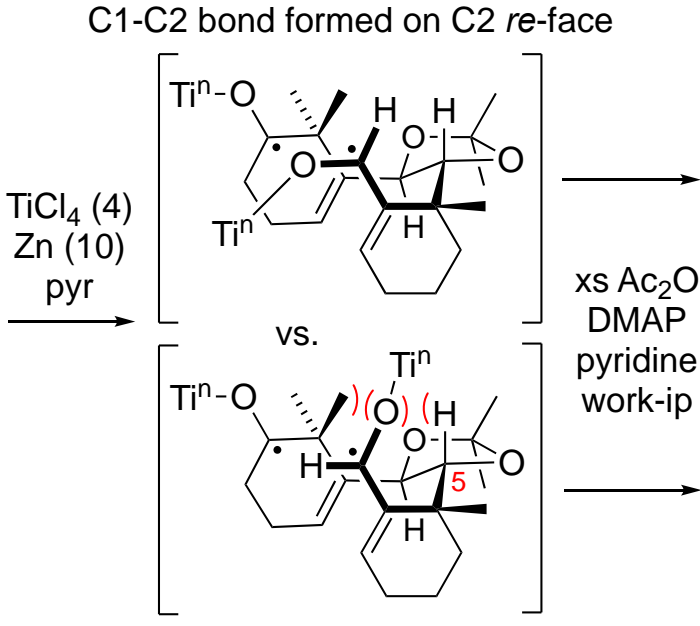

C1-C2 bond formed on C2 si-face

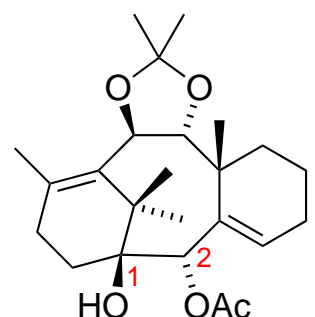

$62(45 \%)$

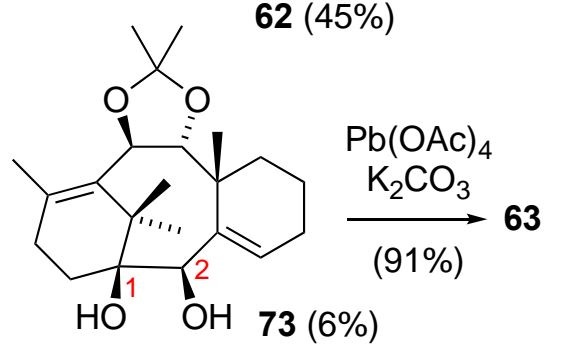

(13)<smiles>Cc1cc(C)[nH]n1</smiles>

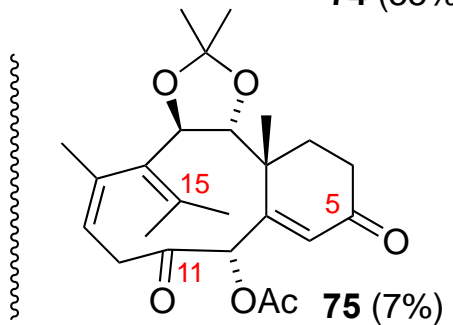

Scheme 13. Closure of B ring by pinacol coupling.

While the oxidation of 62 to 74 introduced oxygen functionality at the desired C5 position, establishment of the C3 stereocenter remained to be accomplished (Scheme 14). To this end, reaction of 74 with tosylhydrazine occurred at the less hindered C5 ketone. Catecholborane reduction took place predominantly on the less hindered re-face to generate an allylic diazine that undergoes [3,3]-sigmatropic rearrangement to afford the desired $(3 R)$-stereocenter present in 76. Catalytic osmium dihydroxylation in a stereofacial fashion, esterification of the more accessible $\mathrm{C} 5$ alcohol with cinnamic acid and oxidation of the C4 alcohol yielded ketone 77. Chemo- and stereoselective nucleophilic addition of methyl Grignard to the C4 ketone gave the corresponding tertiary alcohol. Acetonide hydrolysis and chemoselective acetylation of the C9 and $\mathrm{C} 10$ secondary alcohols in the presence of the $\mathrm{C} 1$ and $\mathrm{C} 4$ tertiary alcohols afforded 78. Attempted dehydration of 78 with Burgess reagent was plagued by rearrangement to afford a 5/7/6 skeleton of the abeotaxane family along with $\mathbf{6 1}$. In order to avoid this rearrangement, the tertiary C1 alcohol of 78 was protected as the dimethylsilylhydride ether, followed by dehydration of the C4 alcohol with Burgess reagent and cleavage of the silyl ether yielded 1-hydroxytaxinine (+)-61. 


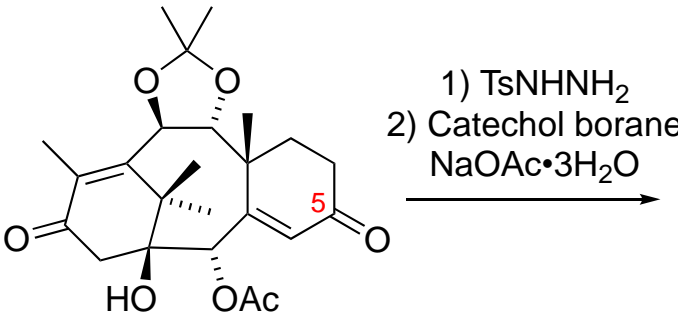

74

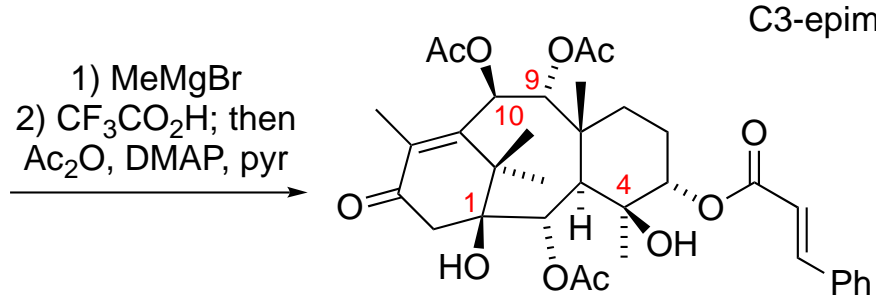

$(+)-78(34 \%)$

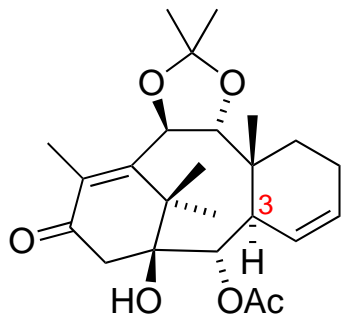
$(+)-76(47 \%)$ and
C3-epimer (21\%)
1) $\mathrm{OsO}_{4}, \mathrm{NMO}$

2) Cinnamic acid

$2,4,6-\mathrm{Cl}_{3} \mathrm{C}_{6} \mathrm{H}_{2} \mathrm{COCl}$

$\mathrm{Et}_{3} \mathrm{~N}, \mathrm{DMAP}$

3) PCC

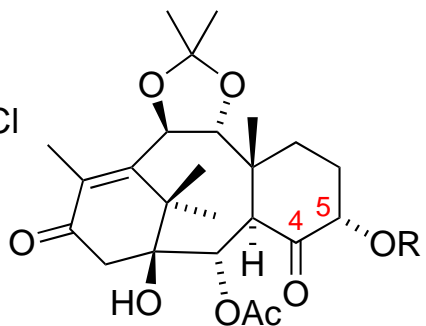

(+)-77, $\mathrm{R}=\mathrm{C}(\mathrm{O}) \mathrm{CH}=\mathrm{CHPh}(58 \%)$

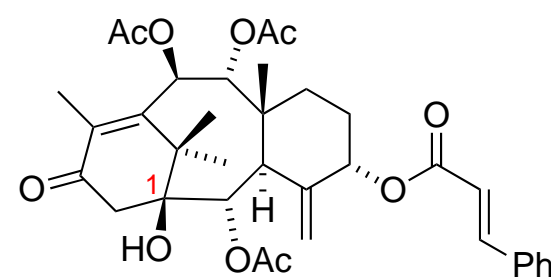

$(+)-61(50 \%)$

Scheme 14. Generation of the C3 stereocenter and completion of the synthesis.

\subsection{Baran total synthesis of taxabaccatin III $(A+C>A C \rightarrow A B C \rightarrow$ oxidase phase)}

Baran's approach for taxol synthesis is inspired by the biosynthesis of terpenes via a two-phase process ${ }^{50}$ which his group has applied to other target molecules ${ }^{51-54}$ including taxabaccatin III (79), ${ }^{55}$ and most recently taxol. ${ }^{56,57}$ Retrosynthetically, the oxidase phase introduces oxygens onto the taxendione skeleton 80 , which was assembled through Diels-Alder cycloaddition of $\mathbf{8 1}$ (Scheme 15). The Diels-Alder precursor was prepared from 3-bromo-2,4-dimethyl-1,3-pentadiene, 3-vinyl-2-cyclohexenone and acrolein.

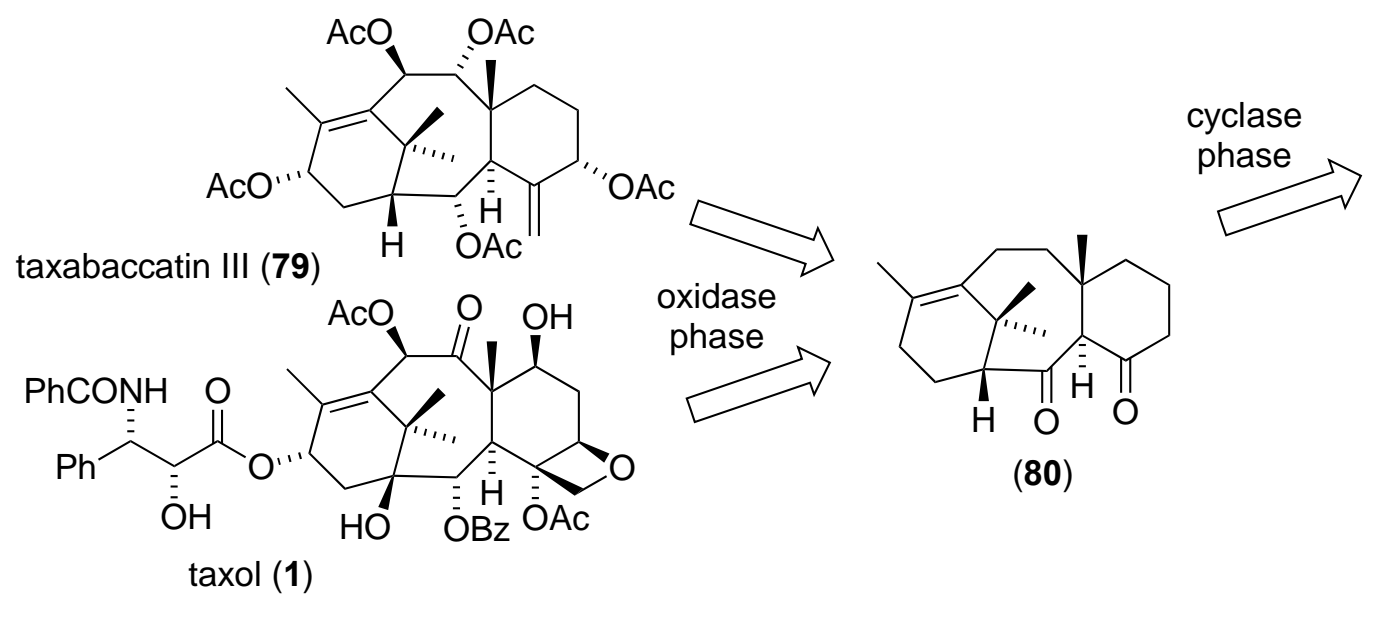

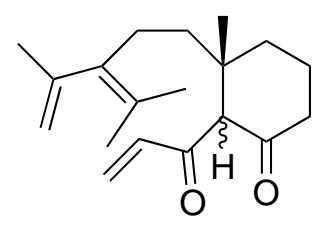

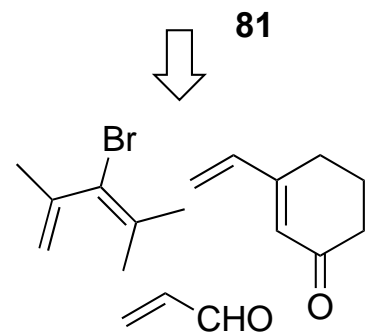

Scheme 15. Retrosynthetic analysis of tax according to Baran's approach.

3.2.1. Process improvements to the synthesis of taxadienone. Refinements of the original ${ }^{58}$ Baran synthesis of (+)-taxadienone (80) have followed the same sequence of reactions, however with improvements for scaleup (Scheme 16). Due to concern for highly energetic nature for the ring opening/elimination of gemdibromocyclopropane (82) to 3-bromo-2,4-pentadiene (83), the process research group at Albany Molecular Research Institute established a continuous flow process for this transformation with a 12.5 min residence time at $150{ }^{\circ} \mathrm{C} .{ }^{59}$ Additionally, the AMRI group established a crystallization protocol for separation/purification 
of $(+)-80(20-22 \%$ isolated yield) from the $\sim 2: 1$ mixture of diastereomers 80 and 85 resulting from the intramolecular Diels-Alder cyclization.

In their recent synthesis of taxol, ${ }^{56,57}$ Baran's group reported using $n$-butyl lithium (in place of $s$-butyl lithium used in their original ${ }^{58}$ synthesis) for the lithium halogen exchange of 83 . A further improvement reported in the recent Baran synthesis concerned a telescoping of the cuprate addition/aldol condensation/oxidation sequence from 86 to the Diels-Alder precursor $\mathbf{8 1 a / b}$. This improvement utilized $N$ heterocyclic carbene ligand (+)-90 (15 mol\%) instead of phophoramidite $(+)-88$ for the cuprate addition and the in situ aldol condensation with acrolein, followed by a DMP oxidation (in place of Jones reagent). Conducting these reactions also avoided the unstable trimethylsilyl enol ether $\mathbf{8 7}$ and shortened overall process time from 3 days to 1 day.

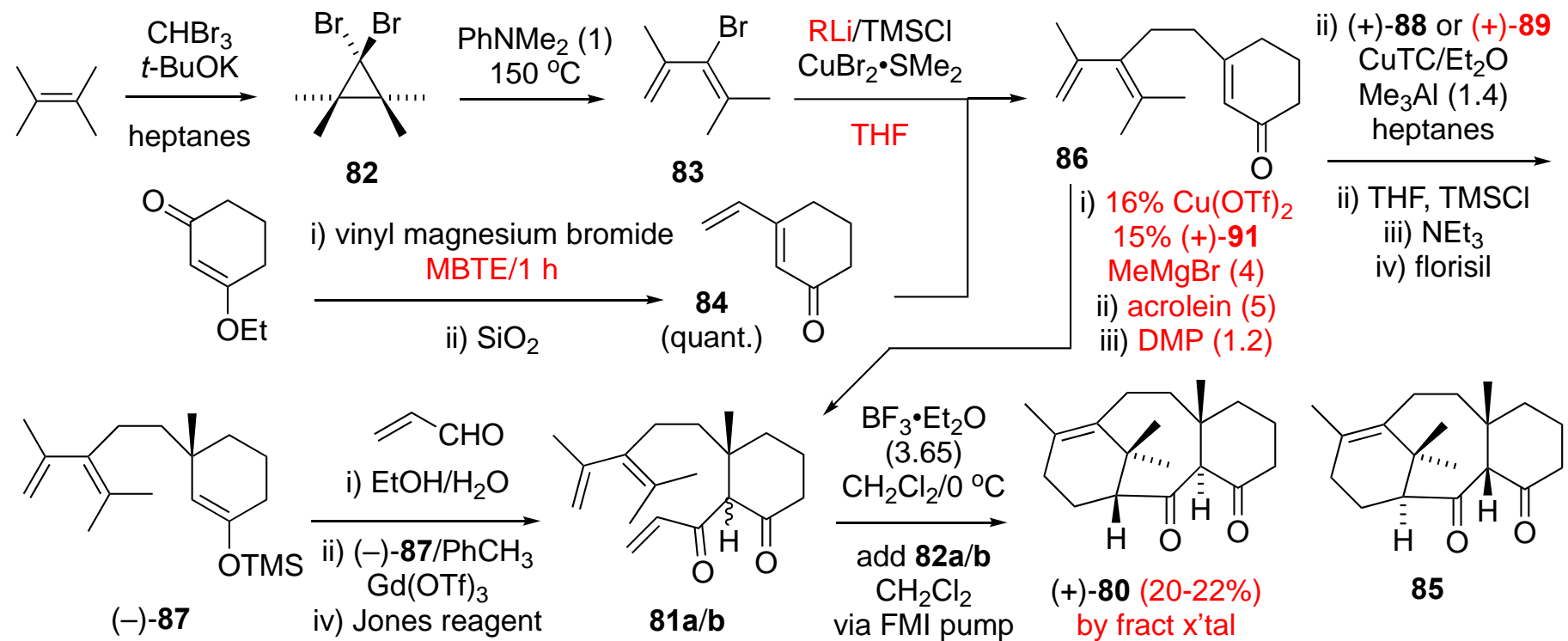

$$
\text { (+)-80 } \underset{\mathrm{KHMDS}(1.5)}{\stackrel{\mathrm{KhNTf}_{2}(2)}{\mathrm{TH} / 0^{\circ} \mathrm{C}}} \frac{\begin{array}{l}
\mathrm{Pd}\left(\mathrm{PPh}_{3}\right)_{4} \\
\mathrm{Me}_{2} \mathrm{Zn}(5)
\end{array}}{\begin{array}{l}
1 \mathrm{~h} / 0^{\circ} \mathrm{C} ; \\
3 \mathrm{~d} / 23^{\circ} \mathrm{C}
\end{array}}
$$

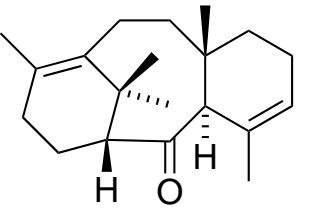

$(+)-82(82 \%)$ recryst from $\mathrm{MeOH}$

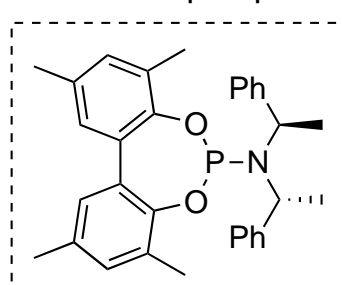

$(+)-88$

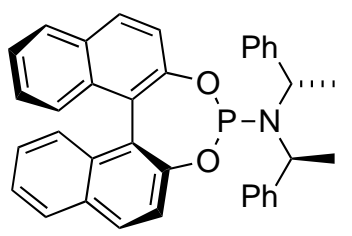

$(+)-89$

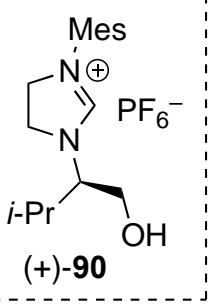

Scheme 16. Synthesis of taxadienone (+)-82 (CuTC $=\operatorname{copper}(\mathrm{I})$-thiophene-2-carboxylate, process improvements in red).

3.2.2. Oxidase phase synthesis of taxabaccatin III. Baran's group utilized taxadienone (+)-82 as the starting point for their oxidase phase synthesis of taxabaccatin III (Scheme 17). ${ }^{55}$ Bouveault-Blanc reduction of 82 with sodium in isopropanol gave 91 along with a minor amount of the C2-epimer. Directed epoxidation with $\mathrm{VO}(\mathrm{acac})_{2}$ followed by alkaline hydrolysis afforded the triol 92, which was protected as the bis-acetate $\mathbf{9 3 .}$ Introduction of the C13 and C10 oxygen atoms was informed by the lessons which were learned in their synthesis of taxuyunnanine D. ${ }^{54}$ Thus, allylic oxidation of $\mathbf{9 3}$, using the $\mathrm{Cr}(\mathrm{V})$ reagent $\mathbf{9 4}$ pioneered in the Baran synthesis of proceeded to give a separable mixture of the desired enone $\mathbf{9 5}$ along with minor amounts of the tertiary allylic alcohol 96. Additionally, oxidation at C10 utilized the radical-mediated protocol with NBS/benzoyl peroxide followed by solvolysis with trimethylsilyl alcohol to yield $\mathbf{9 7}$. Dehydration of 97 with 
Burgess reagent and subsequent treatment with excess DIBAL effected reduction at C13 as well as removal of the acetate groups at $\mathrm{C} 2$ and $\mathrm{C} 5$. The resultant triol was protected as the tris-MOM ether, followed by selective oxidation of the C10 silyl ether to generate the ketone 99. Introduction of the C9 ketone relied on treatment of the enolate anion of 99 with "MoOPh", 60 and CuOAc oxidation of the resultant $\alpha$-hydroxyketone led to 100. A sequential application of $\mathrm{LiAlH}(\mathrm{O} t-\mathrm{Bu})(s-\mathrm{Bu})_{2}$ and sodium amalgam generated diol 101, which embodied all of the oxygen functionality in the correct positions with the correct stereochemistry. The synthesis was completed by acetylation of the C9 and C10 alcohols, mild removal of the three MOM protecting groups and acetylation of the C2, C5 and C13 alcohols.

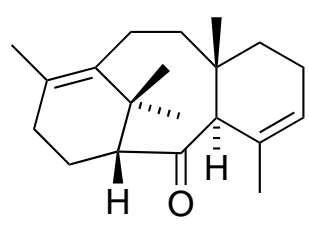

$(+)-82$

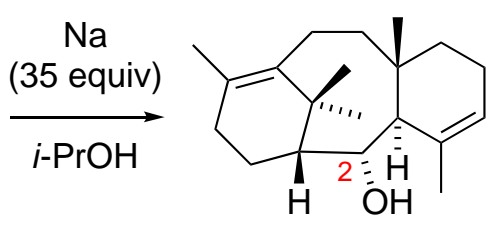

$(+)-91(63 \%)$ + C2-epimer (11\%)
1) $t-\mathrm{BuOOH}$
$5 \% \mathrm{VO}(\mathrm{acac})_{2}$
$\underset{\text { 2) } 3 \mathrm{M} \mathrm{NaOH}}{\mathrm{DMSO} /}$

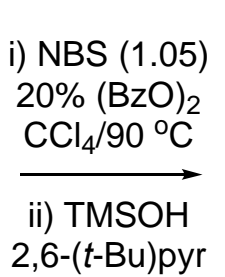

iii) $\mathrm{AgOTf}(5)$

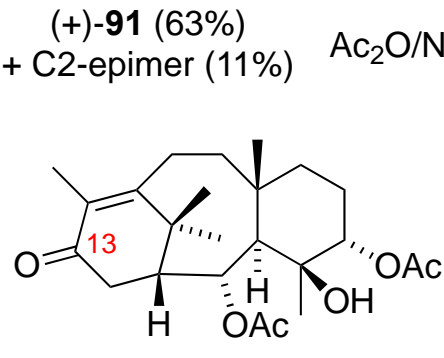

(+)-95 (50\%)

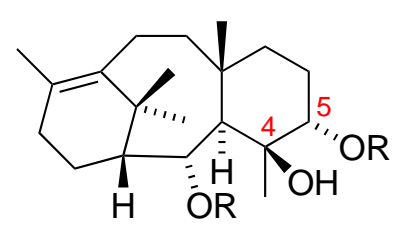

$(+)-92, \mathrm{R}=\mathrm{H}(67 \%)$

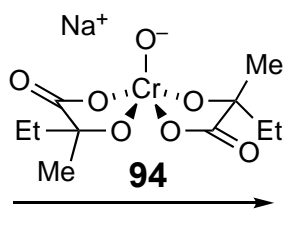

$(+)-93, R=A c(89 \%)$

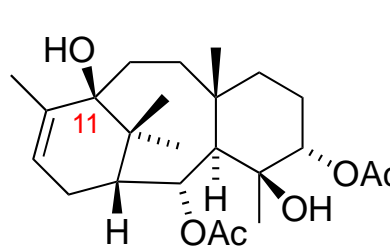

(+)-96 (29\%)

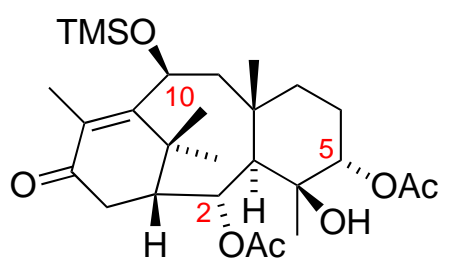

(+)-97 (79\%)

\section{i) Burgess reagent $\mathrm{PhCH}_{3}$ \\ ii) xs DIBAL}

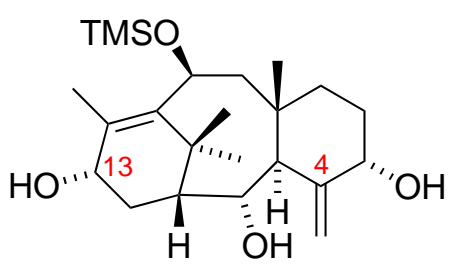

(+)-98 (81\%)

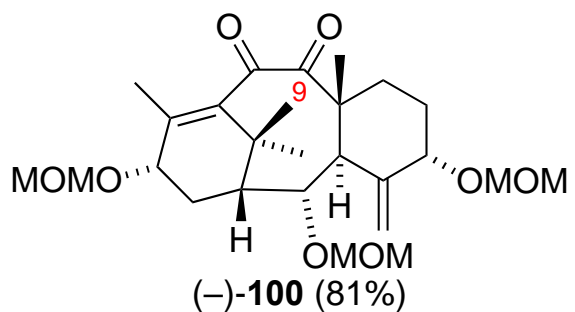

$(-)-100(81 \%)$ i) NaHMDS (12) $\mathrm{MOMCl}(12)$ ii) IBX (26)

$\mathrm{DMSO} / 80^{\circ} \mathrm{C}$

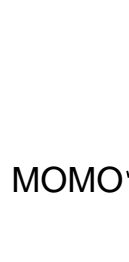

Oי' i) $\mathrm{LiNEt}_{2}(2)$ $\mathrm{MoOPh}(4)$

ii) $\mathrm{CuOAc}(40)$ $\mathrm{MeOH}$
(+)-99 (81\%)

i) $\operatorname{LiAl}(\mathrm{OtBu})(s \mathrm{Bu})_{2}$

ii) $\mathrm{Na}(\mathrm{Hg}) / \mathrm{MeOH}$

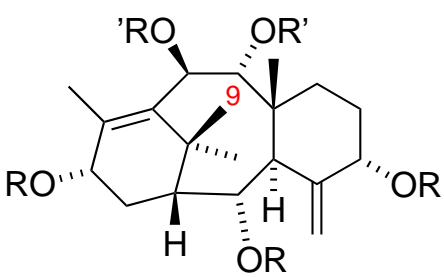

Scheme 17. Baran oxidase phase synthesis of taxabaccatin III.

\subsection{Baran oxidase phase synthesis of taxol}

While the Baran oxidase phase syntheses of (-)-taxuyunnanine $D^{54}$ and (+)-taxabaccatin 1 II $^{55}$ proceeded in relatively short order from taxadienone $(+)-82$ ( 5 and 13 steps respectively), application of this strategy to the total synthesis of taxol presented considerable challenge. This is due not only to the need to introduce six oxygen atoms but also two of these sites are the secondary neopentyl carbon (C7) and the bridgehead quaternary carbon (C1). The supporting information for the Baran synthesis outlines numerous unsuccessful 
attempts at directed $\mathrm{C}-\mathrm{H}$ oxidation at these two positions. Due to these failures, it was necessary to introduce a C5-C6 olefin to facilitate oxidation at C7.

The oxidase phase commenced from the diketone (+)-80 (Scheme 18), 56,57 and utilized oxidation protocols at C13 and C10 similar to those pioneered in the (-)-taxuyunnanine $\mathrm{D}^{54}$ and (+)-taxabaccatin $11 \mathrm{I}^{55}$ syntheses. Thus, allylic oxidation using the $\mathrm{Cr}(\mathrm{V})$ oxidant 94 proceeded at both $\mathrm{C} 13$ as well as at $\mathrm{C} 11$ to generate a mixture of 102 and 103; regio- and enantioselective bromination of this mixture using $\mathrm{CuBr}_{2} \mathrm{gave}$ 104 after purification. Radical allylic bromination of 104 followed by silver mediated substitution by triethylsilanol generated 105. Elimination of $\mathrm{HBr}$ introduced the $\mathrm{C5}-\mathrm{C} 6$ olefin which would eventually be crucial for oxidation at C7. The differential reactivity of the three carbonyl groups in $\mathbf{1 0 6}$ allowed for sequential reaction with methylmagnesium bromide, then DIBAL and finally LiAID $_{4}$ to give triol 107, which was protected at the secondary allylic alcohol. Oxidation using excess dimethyldioxirane (DMDO) proceeded predominantly at the bridgehead $\mathrm{C} 1$ and the less hindered C5-C6 olefin to generate 109, along with minor amounts of the keto epoxide 110. Deuterium labelling at C2 of $\mathbf{1 0 8}$ was necessary, since attempted oxidation of the protioversion of $\mathbf{1 0 8}$ with DMDO proceeded predominantly via C2 alcohol oxidation instead of C1 hydroxylation. Thus, deuterium labelling at C2 suppressed this alcohol oxidation via a kinetic isotope effect. The keto epoxide 110 could be further processed into additional 109 by Sml mediated reduction of the C2 ketone, followed by treatment of $\mathbf{1 1 1}$ with excess DMDO.

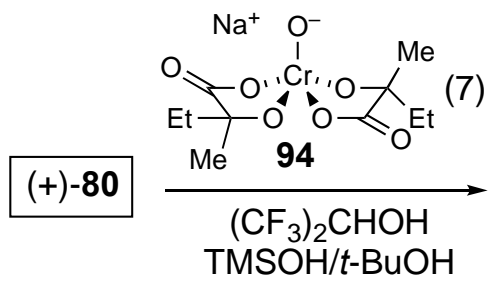

$\mathrm{TMSOH} / \mathrm{t}-\mathrm{BuOH}$

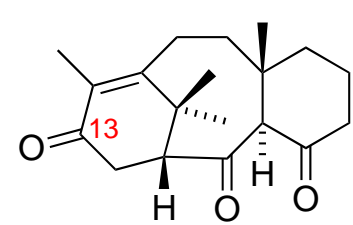

$(+)-102$

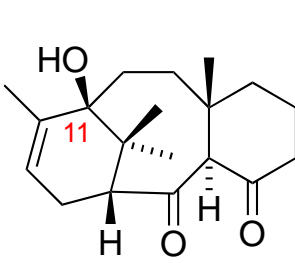

$(+)-103$

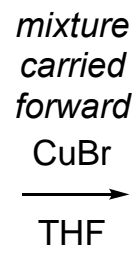

THF

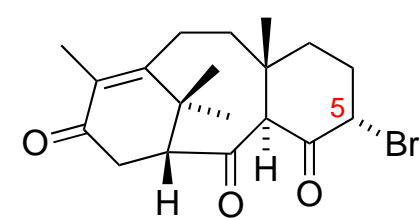

(+)-104 (55\%, two steps)
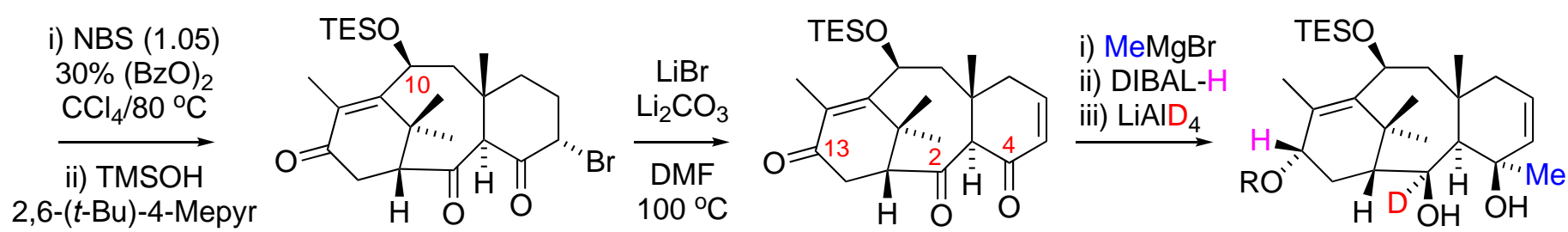

$(+)-105$ (68\%)

(+)-106 (88\%)

NaHMDS/TBSCl

$(+)-107, \mathrm{R}=\mathrm{H}(74 \%)$

$(+)-108, R=$ TBS $(94 \%)$

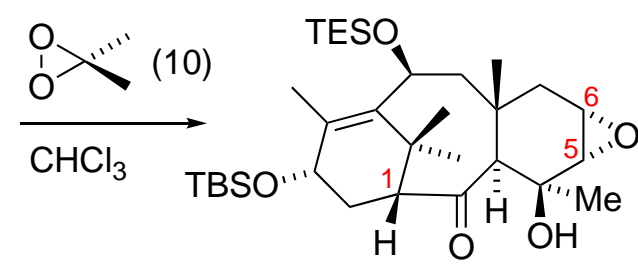

(+)-110 (12\%)
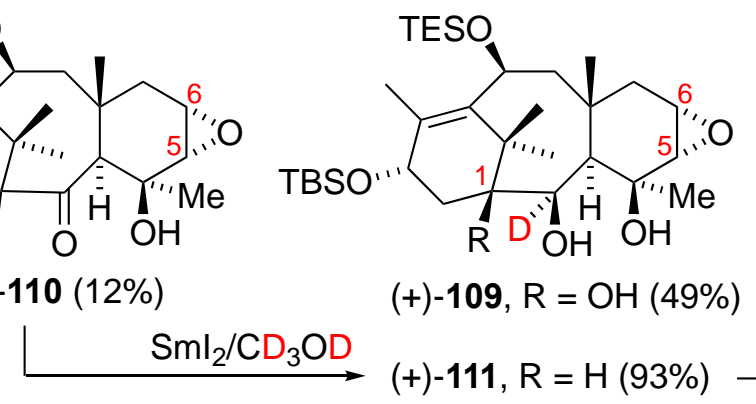

$(+)-109, \mathrm{R}=\mathrm{OH}(49 \%)$
$(+)-111, \mathrm{R}=\mathrm{H}(93 \%)$

DMDO

$\mathrm{CHCl}_{3}$

Scheme 18. Synthesis of taxaepoxide 109.

Notably, at this stage the stereochemistry at C2 of 109 is opposite to that desired in taxol. The stereochemistry was corrected by an oxidation/reduction sequence, followed by reaction with triphosgene to give the cyclic carbonate 112 (Scheme 19). Lewis acid activated epoxide opening with tetrabutylammonium 
iodide, separating the boron salts with 2-fluoropyridine, and protection of the resultant iodohydrin as the TMS ether was followed by iodine oxidation with DMDO leading to a syn-elimination. The resultant C6-C7 olefin was epoxidized with further application of DMDO. Titanium mediated epoxide ring opening of 113 in the presence of triethylsilane proceeded regioselectively at the less hindered C6 carbon to give 114; the $\mathrm{C7}$ alcohol was protected as a BOM ether. Sequential treatment of $\mathbf{1 1 5}$ with Burgess reagent followed by HF-pyridine gave a nearly equimolar, but separable, mixture of ketone 116 along with allylic alcohol 117; this latter product closely resembled an intermediate in the Holton synthesis ${ }^{7}$ except that it possessed the opposite stereochemistry at C10. Introduction of the oxetane D ring closely followed the precedent set by the Florida State group (as well as that in the Chida formal synthesis ${ }^{42,43}$ ). To that end mesylation, followed by dihydroxylation with stoichiometric $\mathrm{OsO}_{4}$, treatment with Hunig's base and oxidation of the C10 TES ether gave ketone 118. Oxidation at C9 with selenic anhydride in the presence of water, followed by redoxisomerization, regeneration of the cyclic carbonate and exhaustive acetylation yielded the diacetate 119. Finally, cleavage of the C13 TBS ether and opening of the carbonate with phenyl lithium yielded 120. Esterification with lactam $\mathbf{1 2 1}$ followed by hydrogenolysis of the BOM ether completed the total synthesis of taxol $[(-)-1]$.

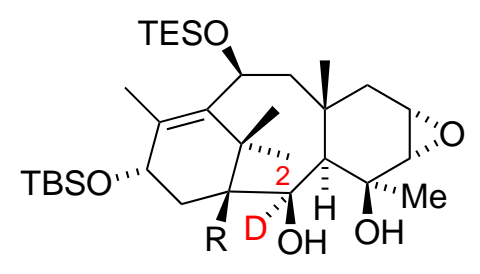

$(+)-109$

i) $\mathrm{TBAI} / \mathrm{BF}_{3} \cdot \mathrm{Et}_{2} \mathrm{O}$;

ii) 2-fluoropyridine;

iii) TMS-imid;

iv) DMDO

v) $\mathrm{DMDO}$

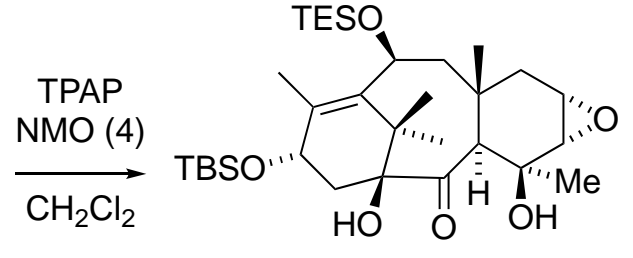

$(81 \%)$

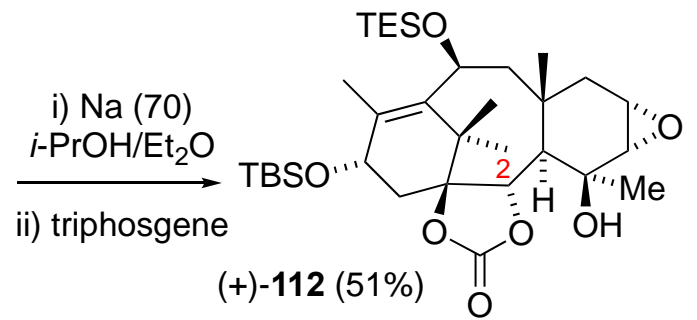

(+)-112 (51\%)

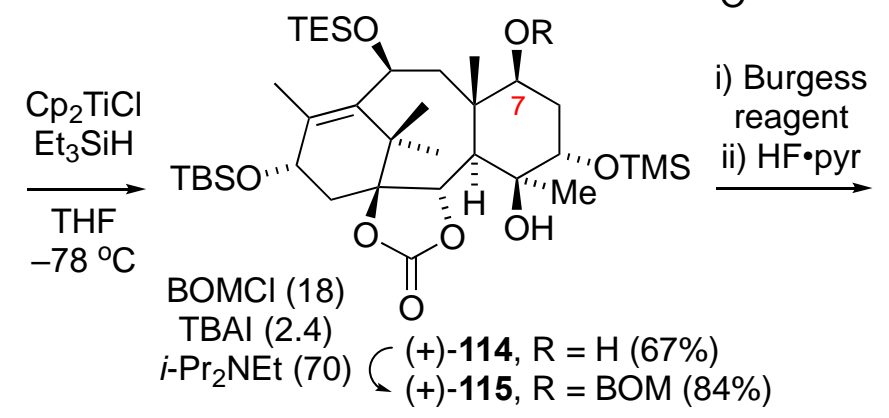

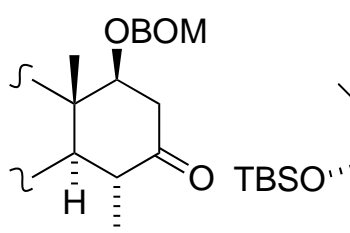

(+)-116 (27\%)

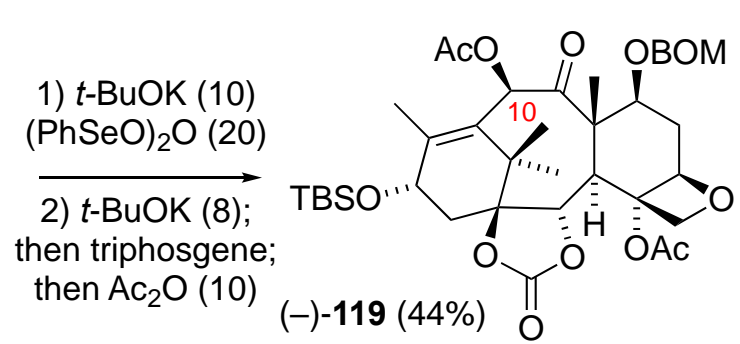

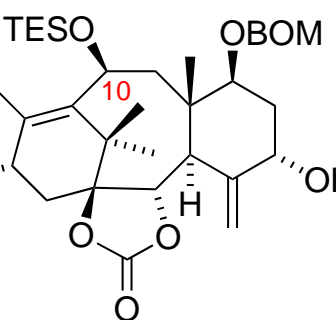

(+)-117 (32\%)

(+)-113 (43\%)
TBAI (2.4)

$i$ - $\mathrm{Pr}_{2} \mathrm{NEt}(70)$

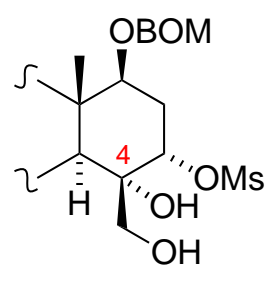

$(68 \%)$

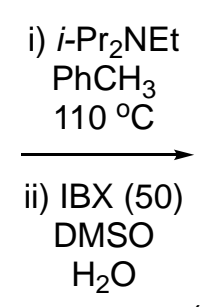

$(+)-118(62 \%)$
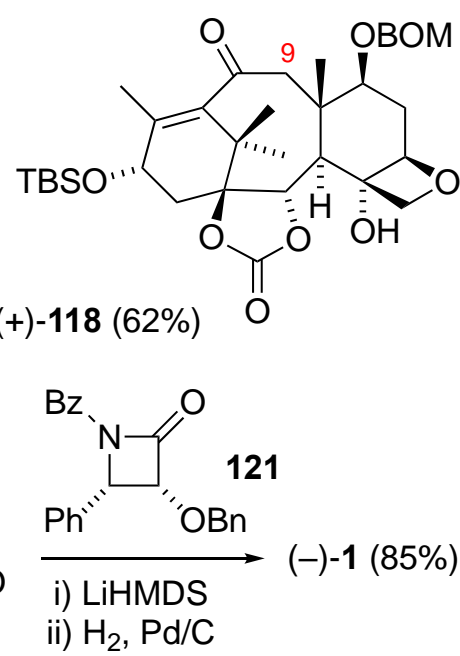

$\mathrm{EtOH}$

Scheme 19. Baran taxol synthesis end-game. 
The Baran two phase enantioselective synthesis of taxol required 27 steps from commercially available achiral tetramethylethylene and 3-ethoxy-2-cyclohexenone resulted in $\sim 0.005 \%$ overall yield. Approximately $1 / 3$ of the steps involved protection or deprotection with approximately $1 / 5$ of the steps were utilized for oxidations or reductions. At the time of their report, a total of $35.2 \mathrm{mg}$ of (-)-1 was produced, representing a 2.5 -fold increase in the next greatest quantity produced by prior total syntheses. ${ }^{12}$ While the Baran synthesis stands as a significant example of the two-phase approach, there are notable downsides. These include a low yield of the key intramolecular Diels-Alder product (80, 20-22\%), low yield for formation of 117 from 115 (32\%), and relatively low conversion of 5,6-epoxide 112 to C7-alcohol 114 (29\%).

\subsection{Gaich synthesis of $( \pm)$ - and (-)-canataxpropellane}

Canataxpropellane (122, Scheme 20) is a highly oxidized, heptacyclic diterpene isolated from Taxus canadensis, the Canadian yew. ${ }^{61}$ It is related to the more common taxoids by virtue of three additional $\mathrm{C}-\mathrm{C}$ bonds, between C3-C11, C4-C12, and C14-C20. The structure of 122 was assigned on the basis of extensive NMR spectral analysis. The authors proposed ${ }^{61}$ that 122 exists as an undefined mixture of interconverting conformers (3:1 ratio), based on an appearance of an additional set of signals in the NMR spectra which they stated showed chemical exchange correlation. No biological data were reported for this compound. Very recently, Gaich's group in Konstanz, Germany reported a total synthesis of both racemic and optically active canataxpropellane. ${ }^{62,63}$ Their retrosynthetic analysis envisioned generation of the cyclopentane $A$ ring by a pinacol coupling of dialdehyde 123. This dialdehyde can be accessed from $\mathbf{1 2 4}$ by B-ring functionalization at C8 and C5 positions via singlet oxygen cycloaddition. Synthetic intermediate $\mathbf{1 2 4}$ would be generated from an intermediate which resulted from a photochemical [2+2] cyclization of $\mathbf{1 2 5}$ which would itself be constructed via Diels-Alder reaction between isobenzofuran 126 and dienophile 127.
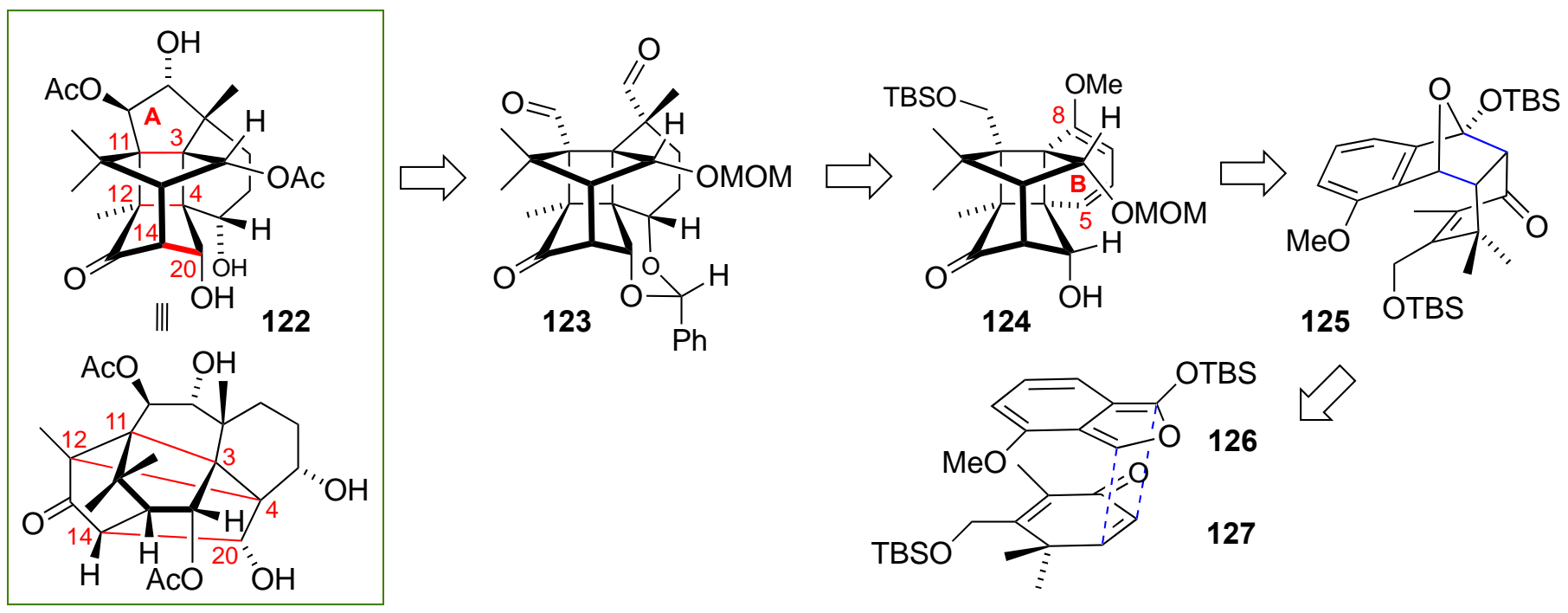

Scheme 20. Gaich retrosynthetic analysis for canataxpropellane.

Dienophile 127 was prepared in three steps from the terpene safranal, by hydration of the distal olefin and oxidation of the $\gamma$-hydroxyenal 128 to give the 2,5-cyclohexadienone 129 (Scheme 21). ${ }^{62}$ Reduction with triacetoxyborohydride, and protection of the primary allylic alcohol afforded 127. Benzylic bromination of methyl 3-methoxy-2-methylbenzoate, followed by lactone formation in the presence of $\mathrm{CaCO}_{3}$ led to 130. 


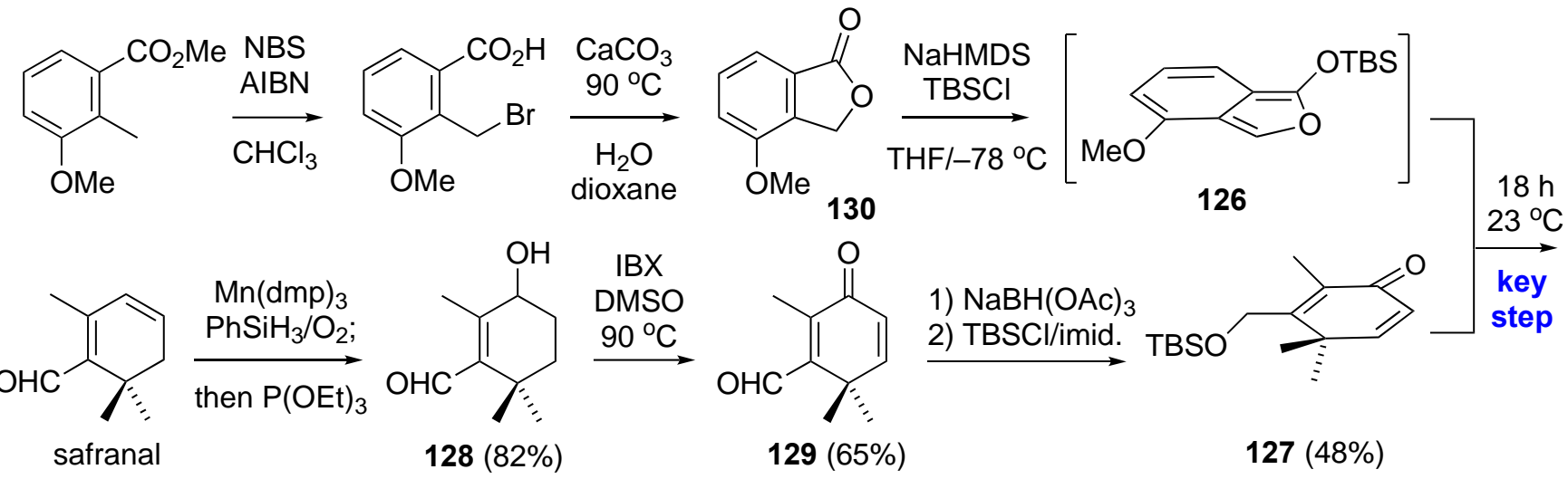

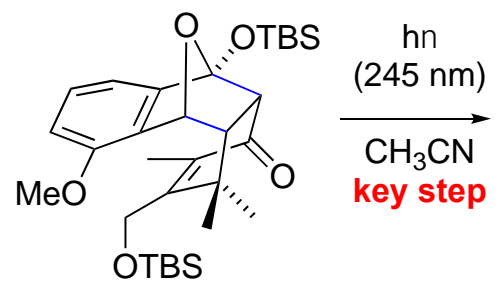

$( \pm)-125(71 \%)$

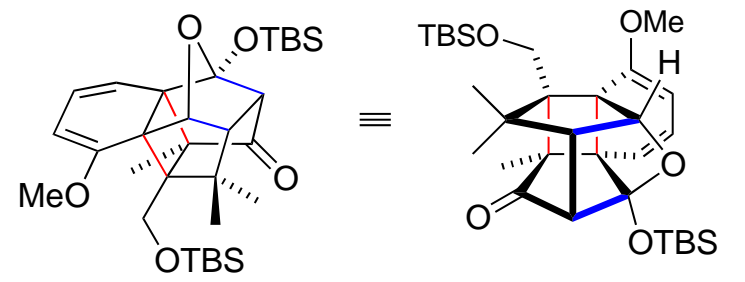

$( \pm)-131(59 \%)+125(35 \%)$

Scheme 21. Preparation of hexacyclic intermediate 124 by Diels-Alder and [2+2] photochemical cyclization.

Treatment of lactone $\mathbf{1 3 0}$ with base followed by quenching with $t$-butyldimethylsilyl chloride gave the isobenzofuran 126 which was not isolated but instead immediately reacted with 127 to give ( \pm )-125 with excellent endo-selectivity. Irradiation of a degassed solution of $\mathbf{1 2 5}$ at $254 \mathrm{~nm}$ afforded ( \pm )-131 along with recovered starting material. Recovered $\mathbf{1 2 5}$ could be recycled to eventually give $71 \%$ of the desired 131 .

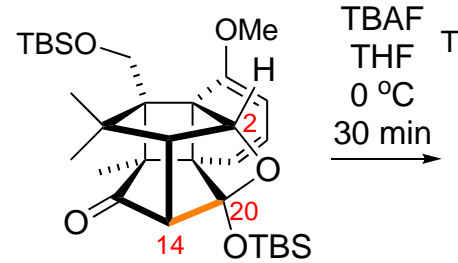

$( \pm)-131$

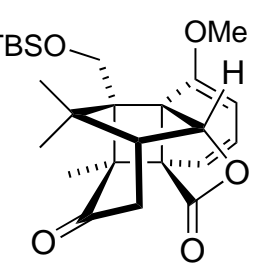

$( \pm)-132$

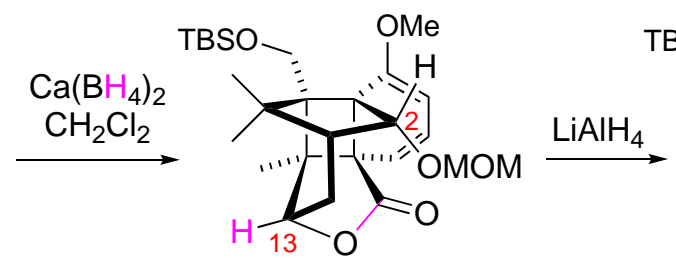

$( \pm)-133, \mathrm{R}=\mathrm{H}$

$( \pm)-134, R=$ MOM $(70 \%, 3$ steps $)$

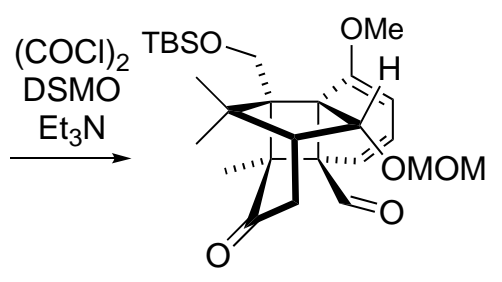

$( \pm)-135$

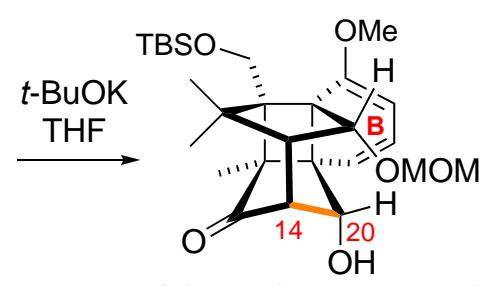

$( \pm)-124(43 \%, 3$ steps $)+( \pm)-135(33 \%)$

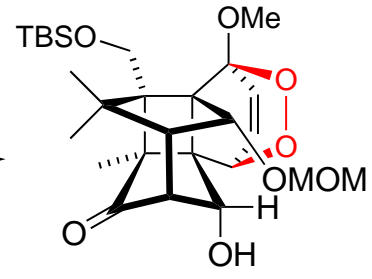

$( \pm)-136$

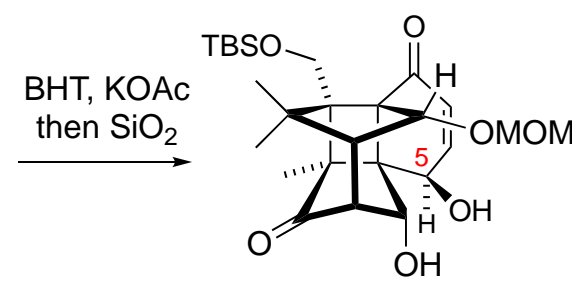

( \pm -137 (71\%, 2 steps) ii) $\underset{\mathrm{IBX} / \mathrm{DMSO} / \mathrm{rt}}{\stackrel{\mathrm{Me}_{4} \mathrm{NBH}(\mathrm{OAc})_{3}}{\longrightarrow}}$ $\mathrm{CH}_{3} \mathrm{CN} / \mathrm{AcOH}$

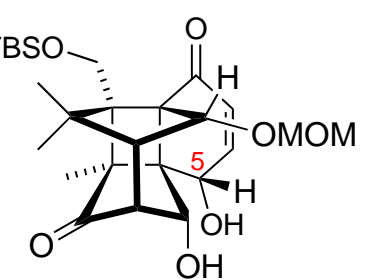

$( \pm)-138(51 \%, 2$ steps $)$

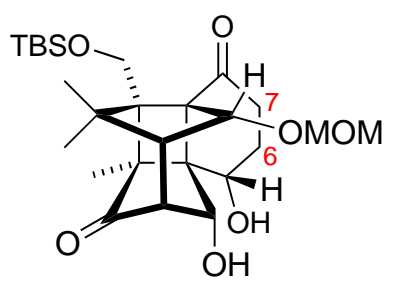

$( \pm)-139(10 \%, 2$ steps $)$

Scheme 22. Generation of the cyclic core of cataxpropellane skeleton via cycloaddition. 
While 131 contains six of the required seven rings present in the target structure along with oxygenation at C2 with the appropriate stereochemistry, cleavage of the C20-bridging oxygen bond required a sequence of 6 steps. To this end, treatment of 131 with TBAF initiated a retroaldol reaction cleaving the C14$\mathrm{C} 20$ bond (Scheme 22). Stereoselective reduction of the resultant ketone 132 resulted in a trans-lactonization to give 133; the C2 alcohol was protected as a MOM ether. Reduction of $\mathbf{1 3 4}$ followed by Swern oxidation and base-mediated aldol condensation reinstalled the $\mathrm{C} 14-\mathrm{C} 20$ bond with appropriate stereochemistry at C20. Attention was next turned to elaboration of the methoxycyclohexadiene B ring. Singlet oxygen cycloaddition gave a single endoperoxide (136) which was immediately reduced with 2,6-di-tert-butyl-4-methylphenol (BHT) to yield hydroxyenone $\mathbf{1 3 7}$ in a good yield. Attempted reduction with other standard endoperoxide reducing agents (thiourea; $\mathrm{H}_{2}$, catalyst; L-selectride; $\mathrm{HN}=\mathrm{NH}$ ) resulted in considerably lower yields. Since the stereochemistry at C5 of $\mathbf{1 3 7}$ was opposite to that required for the target molecule, an oxidation/reduction sequence was used to generate the desired hydroxyenone 138, along with a minor amount of the product resulting from reduction of the C6-C7 olefin (139). The structure of 138 was secured by X-ray crystallographic analysis.

Either 138 or 139 could be converted into the benzylidene acetal 140 (Scheme 23). Vinyl triflate formation from 140 using Comin's reagent to convert the carbonyl to an enol triflate, set the stage for Pdcatalyzed carboxymethylation. Reduction of the resultant enoate 141 with $\mathrm{Mg}$ in methanol produced a saturated ester which underwent deprotonation and $\alpha$-methylation with iodomethane to afford 142. Reduction of 142 with $\mathrm{LiAlH}_{4}$ and treatment with TBAF led to diol 143. Bisaldehyde 144, generated by Swern oxidation of 143, was subjected to a pinacol coupling with $\mathrm{TiCl}_{4} / \mathrm{Zn}$ metal to yield diol 145 as a single stereoisomer, which comprises the complete carbon skeleton and oxidation level of the target, cantaxpropellane. To complete the synthesis, 145 was peracetylated, before deprotectection of the MOM ether with 2-bromo-1,3,2-benzodioxaborole gave a separable mixture of alcohol 148 and triol 147; this latter product could be recycled into additional 148 by reintroducing the benzylidene acetal. The less sterically hindered C9 acetate underwent selective methanolysis and the resulting diol was selectively acetylated at the $\mathrm{C} 2$ alcohol. Finally reductive removal of the benzylidene acetal gave rac-cantaxpropellane ( \pm )-122. Notably, the NMR spectral data for synthetic 122 matched the major set of signals from the isolation work reported by Kiyota's group. ${ }^{61}$ For this reason, Graich suggested ${ }^{62}$ that the second set of signals found in their isolation product may be due to a related derivative of 122 rather than a conformer.

Since the cycloaddition of achiral components 126 and 127 generates racemic 125, a synthesis of (-)122 would require either an enantioselective Diels-Alder reaction, or separation of enantiomers or diastereomers at some early stage. Attempts to use Lewis or Bronsted acid catalysts for the Diels-Alder reaction led to decomposition of the cycloadduct 125. Reaction of the anion generated from lactone 130 with a TADDOL based silyl chloride 150 yielded chiral isobenzofuran 151, which upon reaction with the cyclohexadienone 127 generated a separable mixture of diastereomers (-)-152 and (-)-153 ( 3:2 ratio) from which pure (-)-152 was isolated in 31\% yield (Scheme 24). Photocycloaddition of 152 gave (-)-154 and treatment with TBAF gave the optically active synthetic intermediate $(-)-132$, which was assessed as $>98 \%$ ee by chiral HPLC. The absolute configuration of (-)-132 was established by X-ray crystal structure analysis [Flack $x=-0.11(7)$; Hooft $y=-0.030(18)]$ as well circular dichroism. Lactol (-)-132 was processed by the same sequence of reactions as in the racemic synthesis to subsequently yield optically active (-)-canataxpropellane. 


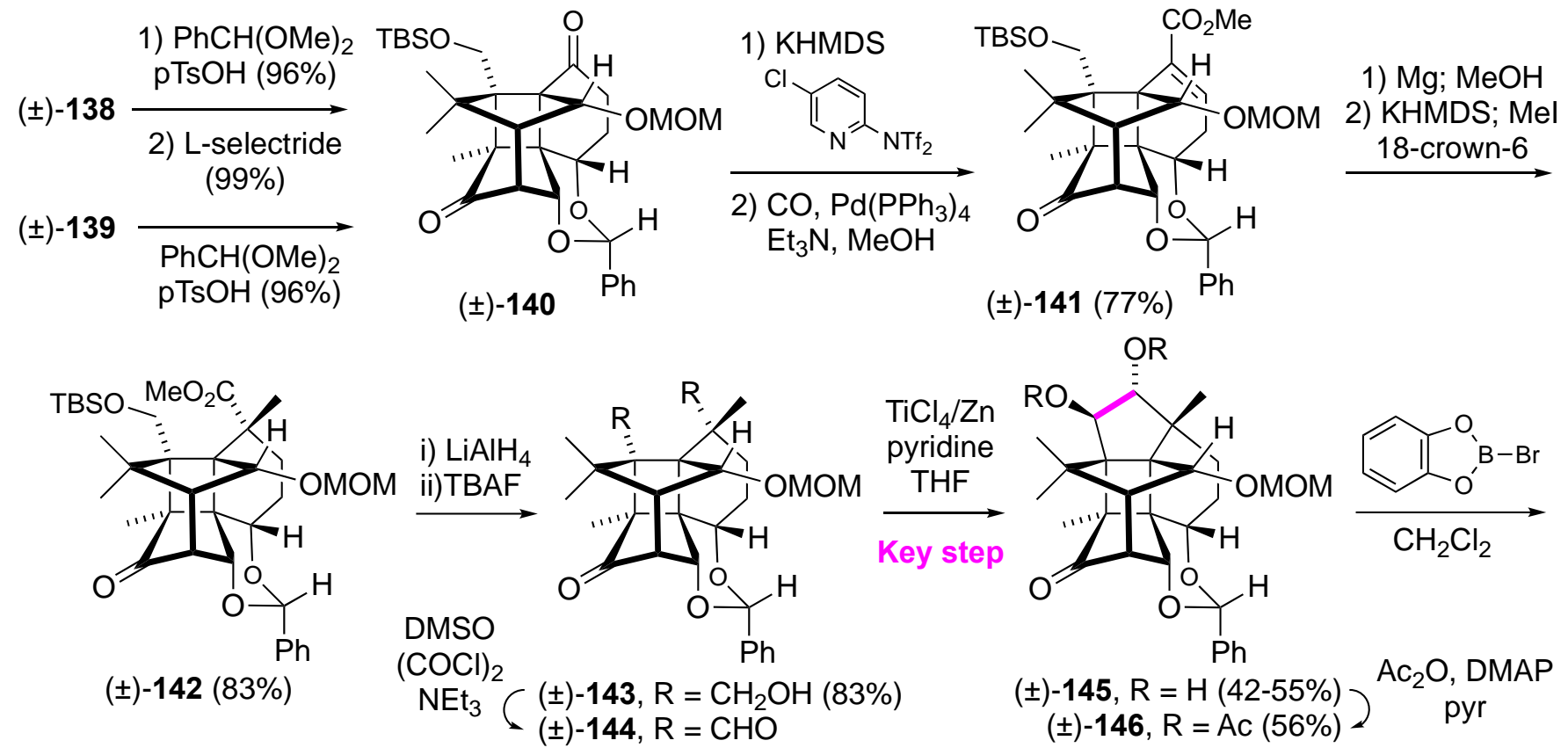

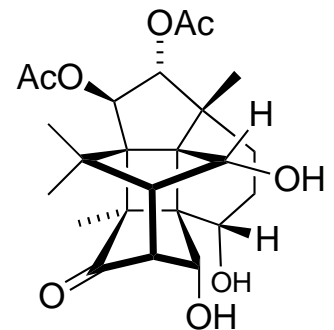

$( \pm)-147(44 \%)$

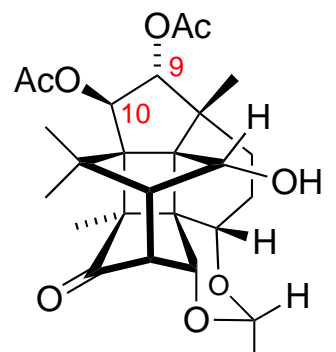

(士)-148 (56\%) $\mathrm{Ph}$

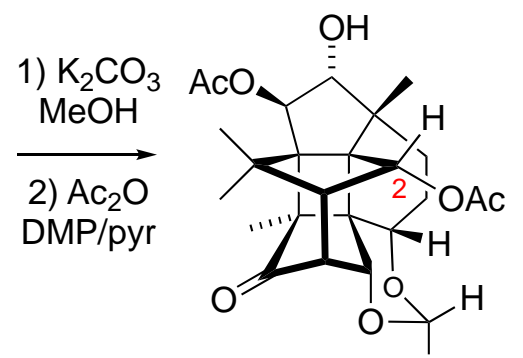

( \pm )-149 (30\%) Ph

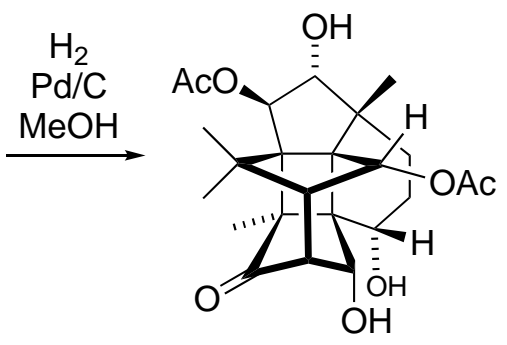

$( \pm)-122(97 \%)$

$\uparrow \mathrm{PhCH}(\mathrm{OMe})_{2} / \mathrm{PTsOH}(67 \%)$

Scheme 23. Completion of the synthesis of rac-cataxpropellane. 


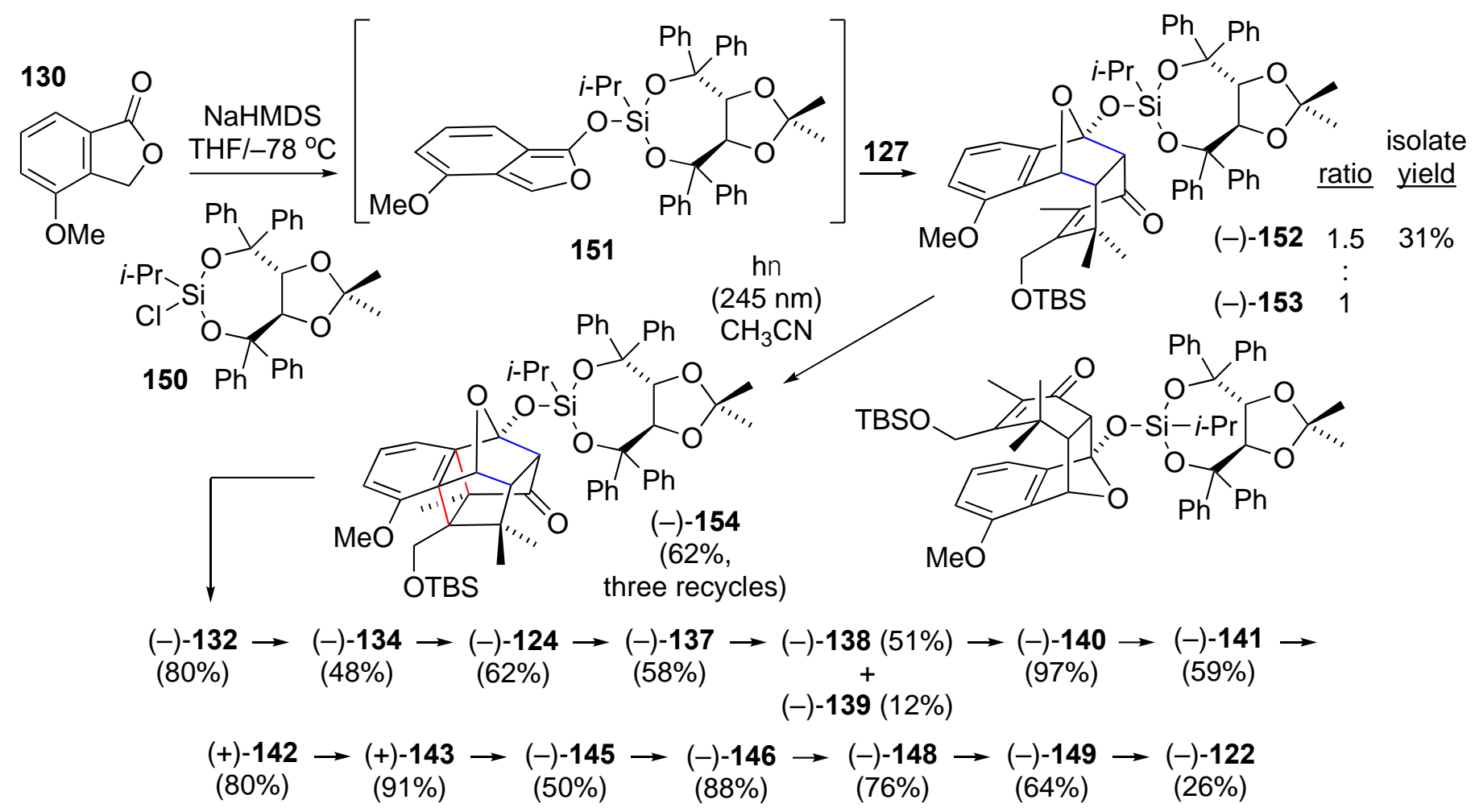

Scheme 24. Synthesis of (-)-canataxpropellane [(-)-122] via separation of Diels-Alder diastereomers.

\section{Conclusions}

While the first syntheses of taxol ${ }^{7-12}$ were reported more than 25 years ago, it is clear from the work of the last 5 years that there is continued interest in this and related targets. Since the industrial preparation of taxol is a semisynthetic route, the value of these total synthesis efforts lies in the development of novel synthetic transformations which might be applied to different targets. Baran's two-phase approach reveals the particular challenge involved in selective $\mathrm{C}-\mathrm{H}$ oxidation at unfunctionalized sites. It might be anticipated that the next frontier to be advanced may focus on the synthesis of other taxoid natural products as represented by the Gaich synthesis of canataxpropellane.

\section{Abbreviations used}

$\mathrm{BHT}=2,6$-di-tert-butyl-4-methylphenol

$\mathrm{BOM}=$ benzyloxymethyl

DBN = 1,5-diazabicyclo[4.3.0]non-5-ene

$\mathrm{DBU}=1,8$-diazabicyclo[5.4.0]undec-7-ene

$\mathrm{DDQ}=$ 2,3-dichloro-5,6-dicyanobenzoquinone

$\mathrm{DIBAL}=$ diisobutylaluminum hydride

DMDO = dimethyldioxirane

DMP = Dess-Martin periodinane (3-oxo-1,3-dihydro-1 $\lambda^{5}$,2-benziodoxole-1,1,1-triyl triacetate)

3,5-DMP = 3,5-dimethylpyrazole 
FDA $=$ Food and Drug Administration

HMPA = hexamethylphosphoramide

LDA = lithium diisopropylamide

$\mathrm{MOM}=$ methoxymethyl

$\mathrm{MoOPH}=$ oxodiperoxymolybdenum(pyridine)-(hexamethylphosphoric triamide)

$\mathrm{NMR}$ = nuclear magnetic resonance

$\mathrm{PCC}=$ pyridinium chlorochromate

TADDOL $=\alpha, \alpha, \alpha^{\prime}, \alpha^{\prime}$-tetraaryl-2,2-disubstituted 1,3-dioxolane-4,5-dimethanol

TBAF = tetra- $n$-butylammonium fluoride

TBS $=t$-butyldimethylsilyl

TES = triethylsilyl

THP = tetrahydropyran

TMS = trimethylsilyl

\section{References}

1. Wani, M. C.; Taylor, H. L.; Wall, M. E.; Coggon, P.; McPhail, A. T. J. Am. Chem. Soc. 1971, 93, $2325-2327$. https://doi.org/10.1021/ja00738a045

2. Wang, Y.-F.; Shi, Q.-W.; Dong, M.; Kiyota, M.; Gu, Y.-C.; Cong, B. Chem. Rev. 2011, 111, 7652-7709. https://doi.org/10.1021/cr100147u

3. Kim, S. H.; Kim, M.-J.; Kim, Y. J.; Chang, H.; Kim, J. W.; Lee, J.-O.; Lee, K.-W.; Kim, J. H.; Bang, S.-M.; Lee, J. S. Medicine (Baltimore) 2017, 96, e8176. https://doi.org/10.1097/MD.0000000000008176

4. Li, Q.; Ma, Z.; Liu, Y.; Kan, X.; Wang, C.; Su, B.; Li, Y.; Yang, Y.; Wang, P.; Lou, Y.; Na, D.; Wang, L.; Zhang, G.; Zhu, X.; Wang, L. FEBS J. 2016, 283, 2836-2852. https://doi.org/10.1111/febs.13767

5. Schiff, P. B.; Fant, J.; Horwitz, S. B. Nature 1979, 277, 665-667. https://doi.org/10.1038/277665a0

6. Holton, R. A.; Somoza, C.; Kim, H. B.; Liang, F.; Biediger, R. J.; Boatman, P. D.; Shindo, M.; Smith, C. C.; Kim, S.; Nadizadeh, H.; Suzuki, Y.; Tao, C.; Vu, P.; Tang, S.; Zhang, P.; Murthi, K. K.; Gentile, L. N.; Liu, J. H. J. Am. Chem. Soc. 1994, 116, 1597-1598. https://doi.org/10.1021/ja00083a066

7. Holton, R. A.; Kim, H. B.; Somoza, C.; Liang, F.; Biediger, R. J.; Boatman, P. D.; Shindo, M.; Smith, C. C.; Kim, S.; Nadizadeh, H.; Suzuki, Y.; Tao, C.; Vu, P.; Tang, S.; Zhang, P.; Murthi, K. K.; Gentile, L. N.; Liu, J. H. J. Am. Chem. Soc. 1994, 116, 1599-1600.

https://doi.org/10.1021/ja00083a067

8. Nicolaou, K. C.; Yang, Z.; Liu, J. J.; Ueno, H.; Nantermet, P. G.; Guy, R. K.; Claiborne, C. F.; Renaud, J.; Couladouros, E. A.; Paulvannan, K.; Sorensen, E. J. Nature 1994, 367, 630-634. https://doi.org/10.1038/367630a0

9. Nicolaou, K. C.; Nantermet, P. B.; Ueno, H.; Guy, R. K.; Couladouros, E. A.; Sorensen, E. J. J. Am. Chem. Soc. 1995, 117, 624-633. https://doi.org/10.1021/ja00107a006 
10. Nicolaou, K. C.; Liu, J. J.; Yang, Z.; Ueno, H.; Sorensen, E. J.; Claiborne, C. F.; Guy, R. K.; Hwang, C.-K.; Nakada, M.; Nantermet, P. G. J. Am. Chem. Soc. 1995, 117, 634-644.

https://doi.org/10.1021/ja00107a007

11. Nicolaou, K. C.; Yang, Z.; Liu, J. J.; Nantermet, P. G.; Claiborne, C. F.; Renaud, J.; Guy, R. K.; Shibayama, K. J. Am. Chem. Soc. 1995, 117, 645-652.

https://doi.org/10.1021/ja00107a008

12. Nicolaou, K. C.; Ueno, H.; Liu, J. J.; Nantermet, P. G.; Yang, Z.; Renaud, J.; Paulvannan, K.; Chada, R. J. J. Am. Chem. Soc. 1995, 117, 653-659.

https://doi.org/10.1021/ja00107a009

13. Masters, J. J.; Link, J. T.; Snyder, L. B.; Young, W. B.; Danishefsky, S. J. Angew. Chem. Int. Ed. 1995, 34, 17231726.

https://doi.org/10.1002/anie.199517231

14. Danishefsky, S. J.; Masters, J. J.; Young, W. B.;Link, J. T.; Snyder, L. B.; Magee, T. V.; Jung, D. K.; Isaacs, R. C.; Bornmann, W. G.; Alaimo, C. A.; Coburn, C. A.; Di Grandi, M. J. J. Am. Chem. Soc. 1996, 118, 2843-2859. https://doi.org/10.1021/ja952692a

15. Wender, P. A.; Badham, N. F.; Conway, S. P.; Floreancig, P. E.; Glass, T. E.; Granicher, C.; Houze, J. B.; Janichen, J.; Lee, D.; Marquess, D. G.; McGrane, P. L.; Meng, W.; Mucciaro, T. P.; Muhlebach, M.; Natchus, M. G.; Paulsen, H.; Rawlins, D. B.; Satkofsky, J.; Shuker, A. J.; Sutton, J. C.; Taylor, R. E.; Tommoda, D. J. Am. Chem. Soc. 1977, 119, 2755-2756.

https://doi.org/10.1021/ja9635387

16. Wender, P. A.; Badham, N. F.; Conway, S. P.; Floreancig, P. E.; Glass, T. E.; Houze, J. B.; Krauss, N. E.; Lee, D.; Marquess, D. G.; McGrane, P. L.; Meng, W.; Natchus, M. G.; Shuker, A. J.; Sutton, J. C.; Taylor, R. E. J. Am. Chem. Soc. 1977, 119, 2757-2758.

https://doi.org/10.1021/ja963539z

17. Morihira, K.; Hara, R.; Kawahara, S.; Nishimori, T.; Nakamura, N.; Kusama, H.; Kuwajima, I. J. Am. Chem. Soc. 1998, 120, 12980-12981. https://doi.org/10.1021/ja963539z

18. Kusama, H.; Hara, R.; Kawahara, S.; Nishimori, T.; Kashima, H.; Nakamura, N.; Morihira, K.; Kuwajima, I. J. Am. Chem. Soc. 2000, 122, 3811-3820.

https://doi.org/10.1021/ja9939439

19. Mukaiyama, T.; Shina, I.; Iwadare, H.; Sakoh, H.; Tani, Y.; Hasegawa, M.; Saitoh, K. Proc. Jpn. Acad. Ser. B 1997, 73B, 95-100.

https://doi.org/10.2183/pjab.73.95

20. Shiina, I.; Iwadare, H.; Sakoh, H.; Hasegawa, M.; Tani, Y.; Mukaiyama, T. Chem. Lett. 1998, 1-2.

21. Shiina, I.; Saitoh, K.; Frechard-Ortuno, I.; Mukaiyama, T. Chem. Lett. 1998, 3-4. https://doi.org/10.1246/cl.1998.3

22. Mukaiyama, T.; Shiina, I.; Iwadare, H.; Sakoh, H.; Nishimura, T.; Ohkawa, N.; Sakoh, H.; Nishimura, K.; Tani, Y.; Hasegawa, M.; Yamada, K.; Saitoh, K. Chem. Eur. J. 1999, 1, 121-161.

https://doi.org/10.1002/(SICI)1521-3765(19990104)5:1<121::AID-CHEM121>3.0.CO;2-O

23. Doi, T.; Fuse, S.; Miyamoto, S.; Nakai, K.; Sasuga, D.; Takahashi, T. Chem. Asian J. 2006, 1, 370-383. https://doi.org/10.1002/asia.200600156

24. Holton, R. A.; Juo, R. R.; Kim, H. B.; Williams, A. D.; Harusawa, S.; Lowenthal, R. E.; Yogai, S. J. Am. Chem. Soc. 1988, 110, 6558-6560. 
25. Paquette, L. A.; Zhao, M. J. Am. Chem. Soc. 1998, 120, 5203-5212. https://doi.org/10.1021/ja9805371

26. Paquette, L. A.; Wang, H.-L.; Su, Z.; Zhao, M. J. Am. Chem. Soc. 1998, 120, 5213-5225. https://doi.org/10.1021/ja980538t

27. Hara, R.; Furukawa, T.; Horiguchi, Y.; Kuwajima, I. J. Am. Chem. Soc. 1996, 118, 9186-9187. ttps://doi.org/10.1021/ja9610949

28. Hara, R.; Furukawa, T.; Kashima, H.; Kusama, H.; Horiguchi, Y.; Kuwajima, I. J. Am. Chem. Soc. 1999, 121, 3072-3082. https://doi.org/10.1021/ja984250f

29. Mukaiyama, T. Tetrahedron 1999, 55, 8609-8670. https://doi.org/10.1016/S0040-4020(99)00437-8

30. Kingston, D. G. I.; Jagtap, P. G.; Yuan, H.; Samala, L. Prog. Chem. Org. Nat. Prod. 2002, 84, 53-225. https://doi.org/10.1007/978-3-7091-6160-9 2

31. Xiao, Z.; Itokawa, H.; Lee, K.-H. Med. Arom. Plants Indust. Profiles 2003, 245-297.

32. Zefirova, O. N.; Nurieva, E. V.; Ryzhov, A. N.; Zyk, N. V.; Zefirova, N. S. Russ. J. Org. Chem. 2005, 41, 315351.

https://doi.org/10.1007/s11178-005-0168-0

33. Wilson, R. M.; Danishefsky, S. J. Chem. Soc. Rev. 2007, 36, 1207-1226. https://doi.org/10.1039/b611967k

34. Urabe, D.; Asaba, T.; Inoue, M. Chem. Rev. 2015, 115, 9207-9231. https://doi.org/10.1021/cr500716f

35. Borah, J. C.; Boruwa, J.; Barua, N. C. Curr. Org. Chem. 2007, 4, 175-199. https://doi.org/10.2174/157017907780598899

36. Hirai, S.; Utsugi, M.; Iwamoto, M.; Nakada, M. Chem. Eur. J. 2015, 21, 355-359. https://doi.org/10.1002/chem.201404295

37. Utsugi, M.; Iwamoto, M.; Hirai, S.; Kawada, H.; Nakada, M. J. Synth. Org. Chem., Jpn. 2017, 75, $1102-1114$. https://doi.org/10.5059/yukigoseikyokaishi.75.1102

38. Mori, K.; Mori, H. Tetrahedron 1985, 41, 5487-5493. https://doi.org/10.1016/S0040-4020(01)91348-1

39. Utsugi, M.; Kamada, Y.; Miyamoto, H.; Nakada, M. Tetrahedron Lett. 2007, 48, 6868-6872. https://doi.org/10.1016/j.tetlet.2007.07.179

40. Hirai, S.; Urushizako, N.; Miyano, M.; Fujii, T.; Nakada, M. Tetrahedron Lett. 2013, 54, 1888-1892. https://doi.org/10.1016/j.tetlet.2013.01.115

41. Momose, T.; Setoguchi, M.; Fujita, T.; Tamura, H.; Chida, N. Chem. Commun. 200, 2237-2238.

42. Fukaya, K.; Tanaka, Y.; Sato, A. C.; Kodama, K.; Yamazaki, H.; Ishimoto, T.; Nozaki, Y.; Iwaki, Y. M.; Yuki, Y.; Umei, K.; Sugai, T.; Yamaguchi, Y.; Watanabe, A.; Oishi, T.; Sato, T.; Chida, N. Org. Lett. 2015,17, $2570-2573$. https://doi.org/10.1021/acs.orglett.5b01173

43. Fukaya, K.; Kodama, K.; Tanaka, Y.; Yamazaki, H.; Sugai, T.; Yamaguchi, Y.; Watanabe, A.; Oishi, T.; Sato, T.; Chida, N. Org. Lett. 2015, 17, 2574-2577. https://doi.org/10.1021/acs.orglett.5b01174

44. Tormakangas, O. P.; Toivola, R. J.; Karvinen, E. K.; Koskinen, A. M. P. Tetrahedron 202, 58, 2175-2181. https://doi.org/10.1016/S0040-4020(02)00089-3

45. Ferrier, R. J.; Prasad, N. J. Chem. Soc. (C) 1969, 570-575. https://doi.org/10.1039/J39690000570 
46. Koto, S. Glycoscience Ed. Fraser-Reid, B. O.; Tatsuta, K.; Thiem, J. Springer-Verlag, Berlin, Germany, 2001, 1, 785-874.

https://doi.org/10.1007/978-3-642-56874-9 24

47. Dauben, W. G.; Michno, D. M. J. Org. Chem. 1977, 42, 682-685.

https://doi.org/10.1021/jo00424a023

48. Ley, S. V.; Norman, J.; Griffith, W. P.; Marsden, S. P. Synthesis 1994, 639-666.

https://doi.org/10.1055/s-1994-25538

49. Imamura, Y.; Yoshioka, S.; Nagatomo, M.; Inoue, M. Angew. Chem. Int. Ed. 2019, 58, 12159-12163. https://doi.org/10.1002/anie.201906872

50. Ishihara, Y.; Baran, P. S. Synlett 2010, 1733-1745.

https://doi.org/10.1055/s-0030-1258123

51. Foo, K.; Usui, I.; Gotz, D. C. G.; Werner, E. W.; Holte, D.; Baran, P. S. Angew. Chem. Int. Ed. 2012,51, 1149111495.

https://doi.org/10.1002/anie.201206904

52. Renata, H.; Zhou, Q.; Baran, P. S. Science 2013, 339, 59-63.

https://doi.org/10.1126/science.1230631

53. Jorgensen, L.; McKerrall, S. J.; Kuttruff, C. A.; Ungeheuer, F.; Felding, J.; Baran, P. S. Science 2013, 341, 878882.

https://doi.org/10.1126/science.1241606

54. Wilde, N. C.; Isomura, M.; Mendoza, A.; Baran, P. S. J. Am. Chem. Soc. 2014, 136, 4909-4912. https://doi.org/10.1021/ja501782r

55. Yuan, C.; Jin, Y.; Wilde, N. C.; Baran, P. S. Angew. Chem. Int. Ed. 2016, 55, 8280-8284. https://doi.org/10.1002/anie.201602235

56. Kanda, Y.; Nakamura, H.; Umemiya, S.; Puthukanoori, R. K.; Appala, V. R. M.; Gaddamanugu, G. K.;

Paraselli, B. R.; Baran, P. S. J. Am. Chem. Soc. 2020, 142, 10526-10533.

https://doi.org/10.1021/jacs.0c03592

57. Kanda, Y.; Ishihara, Y.; Wilde, N. C.; Baran, P. S. J. Org. Chem. 2020, 85, 10293-10320. https://doi.org/10.1021/acs.joc.0c01287

58. Mendoza, A.; Ishihara, Y.; Baran, P. S. Nature Chem. 2012, 4, 21-25.

https://doi.org/10.1038/nchem.1196

59. Krasutsky, S. G.; Jacobo, S. H.; Tweedie, S. R.; Krishnamoorthy, R.; Filatov, A. S. Org. Process Res. Dev. 2015, 19, 284-289.

https://doi.org/10.1021/op500314c

60. Vedejs, E.; Engler, D. A.; Telschow, J. E. J. Org. Chem. 1978, 43, 188-196

https://doi.org/10.1021/jo00396a002

61. Huo, C.-H.; Su, X.-H.; Wang, Y.-F.; Zhang, X.-P.; Shi, Q.-W.; Kiyota, H. Tetrahedron Lett. 2007, 48, $2721-2724$. https://doi.org/10.1016/j.tetlet.2007.02.063

62. Schneider, F.; Samarin, K.; Zanella, S.; Gaich, T. Science 2020, 367, 676-681.

https://doi.org/10.1126/science.aay9173

63. Reuss, F.; Heretsch, P. Angew. Chem. Int. Ed. 2020, 59, 10232-10234.

https://doi.org/10.1002/anie.202002118 


\section{Authors' Biographies}

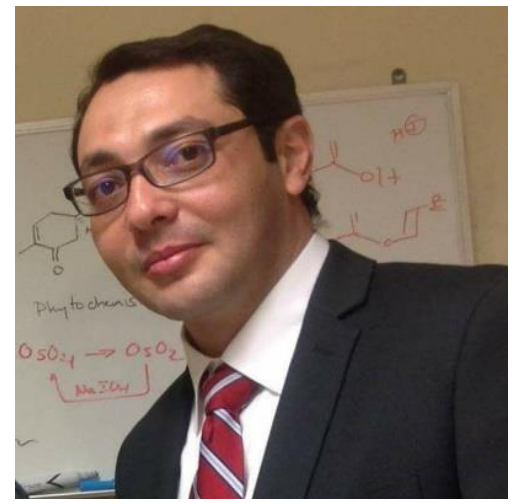

Dr. Mohamed Elmansy was born in Mansoura, Egypt. He received his BSc in Chemistry in 1999, faculty of science, Mansoura University. He was fond of organic chemistry that motivated him to continue his master in organic chemistry at the same university under the supervision of Prof. Ahmed A. Fadda. He did his PhD at Marquette University, USA under the supervision of Prof. William A. Donaldson conducting medicinal chemistry research focused on the synthesis of novel aminocyclitols as glycosidases inhibitors using organoiron chemistry. His postdoctoral research at Oregon State University, USA, under the supervision of Prof. Rich G. Carter, focused on reaction development and total synthesis of natural product. For a short period of time, he joined Prof. Paul Blakemore lab at Oregon State where his research focused on novel systematic synthesis of alkenes by eliminative cross-coupling of enantioenriched sp $^{3}$-hybridized carbenoids. Dr. Elmansy holds an Associate Professor position at the National Research Centre, Egypt and researcher position in Prof. Richard Silverman's research group, Northwestern University, USA working on development of a new treatment for amyotrophic lateral sclerosis.

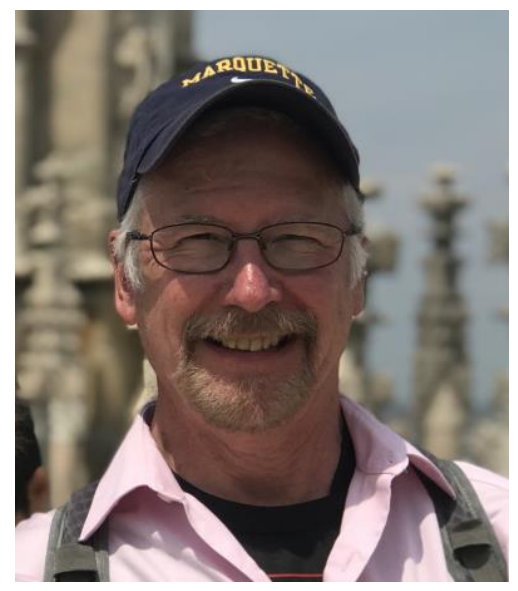

William A. Donaldson was born near Philadelphia, Pennsylvania. He received his B.A. degree in Chemistry from Wesleyan University (1977), and his Ph.D. in Organometallic Chemistry from Dartmouth College (1981) working with Prof. Russell Hughes, before conducting postdoctoral research with the late Prof. Myron Rosenblum at Brandeis University (1981-1982). He joined the faculty at Marquette University in 1983, rising through the ranks to full professor in 1996. He held an Alexander von Humboldt research fellowship at Philipps Universitat-Marburg (1990-1991) and was a Visiting Professor at the University of Strathclyde (2015). His research has centered on the application of organoiron complexes to organic synthesis, synthesis of hydropyran natural products and generation of molecular complexity from simple hydrocarbons. More recently, his research has focused on the development of estrogen receptor- $\beta$ selective agonists. He is a co- 
founder and President of a start-up company, Estrigenix Therapeutics. Upon retiring from formal teaching and service from Marquette he will be employed with managing and directing the synthetic efforts at Estrigenix.

This paper is an open access article distributed under the terms of the Creative Commons Attribution (CC BY) license (http://creativecommons.org/licenses/by/4.0/) 